\title{
Analysis of the Influence of Residual Stress on Fatigue Life of Welded Joints
}

\author{
Ronaldo Cesar Tremarin ${ }^{a, b *}$ (D) , Zacarias Martin Chamberlain Pravia ${ }^{a}$ \\ a Programa de Pós-graduação em Engenharia Civil e Ambiental (PPGEng), Universidade de Passo Fundo (UPF), Passo Fundo, Brasil. \\ E-mail: ronaldo.tremarin@erechim.ifrs.edu.br, zacarias@upf.br \\ b Instituto Federal do Rio Grande do Sul (IFRS), Campus Erechim, RS, Brasil \\ * Corresponding author
}

http://dx.doi.org/10.1590/1679-78256020

\begin{abstract}
This work presents a new computational approach to estimate the fatigue life in welded joints, taking into account three-dimensional, non-proportional, and out-of-phase stresses; the thermomechanical properties of steel; parameters of the welding process; and the effects of residual stresses. We use the mechanical equations of continuous and cumulative fatigue damage found from Multiaxial RainFlow, the Wang and Brown and critical plane methods, and the Findley criteria approach. The numerical finite element method, available with software, is used to simulate the formation of residual stress and quantify its influence by solving equations. Based on the analysis of numerical results, we were able to prevision the crack location and angles of propagation of a high cycle fatigue crack with totally random loads in a metallic structure. We conclude that the result of the computational method is valid and can be used to estimate and life in fatigue in welded joints.
\end{abstract}

\section{Keywords}

welded joint, residual stress, multiaxial fatigue, finite elements

\section{Graphical Abstract}

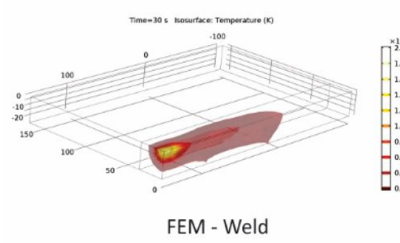

FEM - Weld

$D=\sum_{i}^{m} d_{j}=\sum_{i}^{m} \frac{n_{j}}{N_{j}} \geq D_{P M}$

Palmgren-Miner Equation

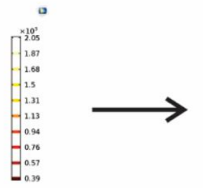

$\leftarrow$
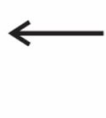

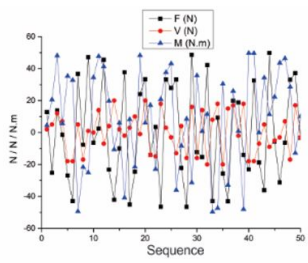

Multiaxial Stress

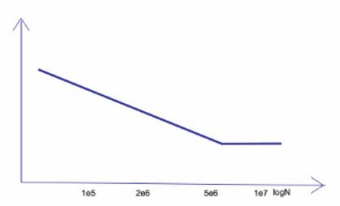

SN
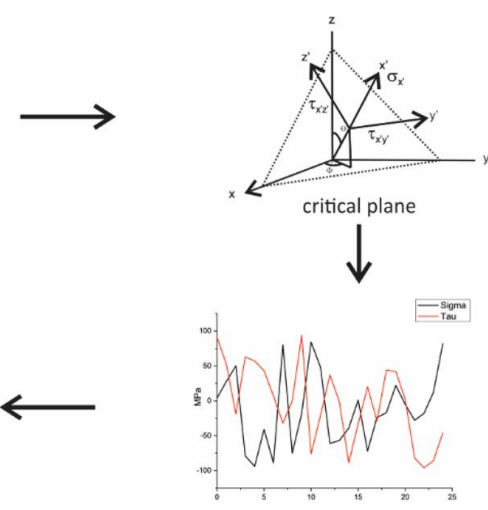


\section{INTRODUCTION}

In many structural applications of steel or composite steel-concrete (QIAN et al., 2014) and (QIAN et al., 2014), for example in bridges, off-shore structures, cars, cargo vehicles, and railway equipment among others, welded joints are usually subjected to three-dimensional, cyclic, non-proportional loads (ESMAEILI et al., 2015) for long periods. According to (HUO; WANG; ZHANG, 2005), welded joint failure represents $80 \%$ of all fatigue failures.

High temperatures developed in the welding process can produce significant metallurgical and mechanical transformations in the fused zone (FZ) and the Heat-Affected Zone (HAZ), reducing reliability. This functional degradation can be modeled using mathematical equations (BUI et al., 1994) and (KOHANDEHGHAN; SERAJZADEH, 2011). According to (HE et al., 2014), the resistance to multiaxial fatigue in the HAZ and the weld metal (WM) are, respectively, $55 \%$ and $60 \%$ lower than that of the base metal (MB).

In the last twenty years, the properties of the MB have been extensively studied. However, the fatigue behavior of welded joints has rarely been investigated, especially in the high cycle fatigue regime (HE et al., 2014).

In the welded joint, the residual stress (RS) appears and remains in the absence of external loads or changes in temperature. It arises because metallic materials have different thermomechanical coefficients and elastic/plastic strain rates as a function of temperature (SILVA et al., 2016).

During the welding process, significant metallurgical changes occur in the MB, HAZ, and FZ (KOHANDEHGHAN; SERAJZADEH, 2011) and (LI et al., 2017), in addition to the evident changes in the mechanical properties between the $M B$ areas and $H A Z$, where RS occurs.

According to (GAN et al., 2016), in the last decades, the RS from the welding process has been the object of study by engineers and designers because it is related to both manufacturing welding process and fatigue life of the component.

Several methodologies are proposed for the study of fatigue in welded joints (KHURSHID et al., 2016): hot spots, structural stress, local stresses,, and modified Wöhler and von Mises (AUSIELLO et al., 2011) curves. Some of these are based on the critical plane model, effective integral method, or an equivalent voltage hypothesis.

As computer simulation tools for structural design and manufacturing processes evolve, there is an inherent need to optimize and automate the analytical or computational tools to estimate fatigue life in various types of welded joints.

The geometric relationship of the welded joint to the direction of the structural stress means that the multiaxial fatigue strength can be optimized for compressive RS or reduced by tractive RS (KREBS; KASSNER, 2007). For these reasons, three-dimensional analysis is necessary for each region of the HAZ under different load conditions.

According to BHATTI et al. (2015) and EISAZADEH et al. (2015), the RS can influence the performance of the multiaxial fatigue of the structure. In this sense, understanding the formation of the RS in the weld and its effects is extremely important for mechanical engineers and designers working in metal industries. The interpretation of the effects of RS on dynamic performance is a challenge, but the effects have been optimized in recent decades (JAMES et al., 2007).

While external loads acting on components are clearly important, other factors, like microstructure and RS, also contribute to failure. In cases where failure cannot be tolerated, engineers must be able to predict the behavior of welded joints, whether via measurements or computer simulations. Knowledge of the RS intensity and directions are essential in such situations (WITHERS, 2007), (SAVARIA; BRIDIER; BOCHER, 2016), and (GADALLAH et al., 2018).

The first objective of this work is to carry out the $3 \mathrm{D}$ heat transfer simulation of the welding process according to Goldak's equation (GOLDAK; CHAKRAVARTI; BIBBY, 1984) and the formation of the RS in the flat welded joint, especially in the HAZ/MB. Next, we perform the numerical modeling of multiaxial stresses from three-dimensional random loads using Comsol Multiphysics (COMSOL, 2019), applying the methods of Wang \& Brown (WANG; BROWN, 1996), Multiaxial RainFlow, and Findley criteria (FINDLEY, 1959). Finally, we predict the fatigue life and determine the crack propagation angle.

The present study represents an advancement of the research into the relationship between the welding process and the fatigue life. According to (GADALLAH et al., 2018), the integrity of the welded structures represents a problem that requires a rigorous analysis, especially for structures exposed to cyclic loads, but also for metallurgical transformations due to transient thermal changes, and for non-uniform heat distribution in the weld region, where adjacent regions have different temperature peaks (LINDGREN, 2006) and (JIA et al., 2014). In these regions, the observed maximum values of temperatures tend to be reduced because of their distance from the displacement line of the heat source. The transient thermal changes are the metallurgical changes observed mainly due to the cooling rate in the temperature range between $1073 \mathrm{~K}$ to $773 \mathrm{~K}$ in each of the sub-regions of a HAZ or even in different HAZs in the same component. 
This is widely recognized as a highly complex problem due to the influence of all the mentioned parameters, in addition to the influence of the chemical composition, the phases and microstructures present in the MB, and, if applicable, the addition metal (MA).

Recent years have seen the development of open code, low-cost methodologies for computer simulations of welding, RS, and fatigue that are versatile and suitable for immediate application in different geometries, steel families, and process variables. The software can be easily adjusted to future needs with additions or deletions of variables in contour or integral parts of the simulations. It provides greater understanding of the phenomena of RS formation and subsequent evolution of the effects in welded structures and can predict the location of the appearance and propagation of the first crack in different geometric positions in a welded metal structure, as well as the angle of propagation of high-cycle fatigue cracks under random, out of phase loads, using Findley criteria (FINDLEY, 1959). In addition to improving the strength of predictions of the effects of RS in life predictions under fatigue, computer simulations can reduce costs, and increase industrial competitiveness, productivity, profitability, and safety of structural projects.

\section{LITERATURE REVIEW}

\subsection{Findley model (1959)}

The fatigue failure process consists of three phases: crack initiation, crack propagation, and rupture of the remaining section due to overload (HOBBACHER et al., 2016). As a rule, the first two stages correspond to $99 \%$ of the component's fatigue life. There are criteria for estimating life in fatigue based on the analysis of stresses, deformations, and energy. The analysis of multiaxial stresses is suitable for high cycle fatigue, the use of deformation is suitable for low cycle fatigue and the methods based on energy analysis can be applied to either stress or deformation analysis (HE et al., 2014).

Some fatigue life prediction models, in the multiaxial case, are based on the set of methodologies cited in (CROSSLAND, 1956) and (SINES, 1959).

According to (PAPADOPOULOS, 2001), the sets of methodologies give more reliable predictions when the stresses appear in phase, as opposed to random, non-proportional, or out of phase tensions.

The critical plane is the method that determines the planes for which deformations and stresses, whether shear $\tau_{n}$ or normal $\sigma_{n}$, define the progress of the nucleation and crack propagation stages.

Several models conceived in recent years employ the approach of the critical plane, among which (BROWN; MILLER, 1973), (FATEMI; SOCIE, 1988) and (MCDIARMID, 1991) stand out. (MAMIYA; ARAÚJO; CASTRO, 2009) concentrated their efforts on developing the methods more suitable for out-of-phase and non-proportional loads.

Methods based on stress analysis that employ the concept of the critical plane (PEDERSEN, 2016), (FATEMI; SOCIE, 1988) and (FINDLEY, 1959) can determine the propagation plane of the crack mathematically (KLUGER; ŁAGODA, 2016). Life in fatigue depends on a combination of stresses acting on that critical plane, which allows the global analysis of stresses and microstructure.

To calculate the damage in fatigue of a high non-proportional and out of phase multiaxial cycle, it is necessary to determine the octahedral $\tau_{n}$ and $\sigma_{n}$ stresses acting in the critical plane, as shown in Figure 1 . The stresses $\tau_{i j}$ and $\sigma_{\mathrm{ij}}$ $(x, y, z)$ are decomposed into $\tau_{i \prime j^{\prime}}$ and $\sigma_{i^{\prime} j^{\prime}}\left(x^{\prime}, y^{\prime}, z^{\prime}\right)$ as a function of the angles of the plane, to help in later determination of the

planes in which the values of the stresses $\tau_{n}$ and $\sigma_{n}$ are maximized (MAMIYA; ARAÚJO; CASTRO, 2009) and (PEDERSEN, 2016).

Figure 1 shows an element on the surface in the cartesian coordinate system $O-X-Y-Z$, in which the values of $\tau_{i / j}$ $\left(x^{\prime}, y^{\prime}, z^{\prime}\right)$ and $\sigma_{i \prime j^{\prime}}\left(x^{\prime}, y^{\prime}, z^{\prime}\right)$ in the $O-X^{\prime}-Y^{\prime}-$ plane $Z$ are obtained. 


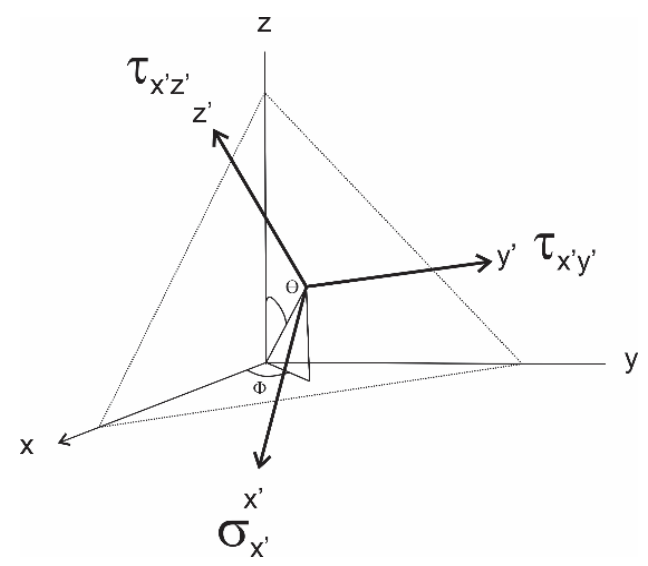

Figure 1 - The $X, Y, Z$ coordinate system, and the $X^{\prime}, Y^{\prime}, Z$ 'auxiliary system, showing a possible critical plane.

According to (EUROCODE 3, 2005) and (KHURSHID et al., 2016), the best method for analyzing life in multiaxial fatigue, in particular in the high-cycle regime of non-proportional, out of phase, and cyclic loading of welded joints, is based on a combination of stress checking $\tau_{n}$ and $\sigma_{n}$. The Findley model (FINDLEY, 1959) is widely used for this purpose in winLiFE ${ }^{\circledR}$ software (WINLIFE - STZ-VERKEHR, 2019) and Comsol Multiphysics ${ }^{\circledR}(C O M S O L, 2019)$.

The Findley criterion was the first to use the concept of cumulative damage at the critical level to determine the angles at which the values on the left side of Equation (1)

$\max \left(\tau_{a}(\Phi, \theta)+k_{f} \max \sigma_{n, \operatorname{máx}}(\Phi, \theta)\right)=\tau_{f}^{*}(2 N)^{b}$

are maximized (ESMAEILI et al., 2015) and (FINDLEY, 1959). This allows the analysis of all of the planes in the multiaxial fatigue cycle. It should be noted that for each fatigue time - $t_{1}(s)$ there is a pair of equidistant planes in which the values of $\tau_{i \prime j^{\prime}}\left(\mathrm{x}^{\prime}, \mathrm{y}^{\prime}, \mathrm{z}^{\prime}\right)$ and $\sigma_{i, j},\left(\mathrm{x}^{\prime}, \mathrm{y}^{\prime}, \mathrm{z}^{\prime}\right)$ are maximized, but for analysis purposes, only one plane is used in the critical plane method (BAPTISTA et al., 2016).

In Equation $1, \tau_{f}^{*}$ is the fatigue strength coefficient, $b$ is the high cycle fatigue strength exponent $k_{f}$ is the sensitivity factor, $\sigma_{n, m a x}$ is the maximum value of the normal stress and $\tau_{a}$ is the amplitude of the shear stress in the cycle.

The parameter $\tau_{f}^{*}(2 N)^{b}$, which is, according to (SOCIE, D. F. \& MARQUIS, 2000), identical to fatigue limit - $\beta_{\mathrm{F}}$, carries within itself the limiting case of the SN fatigue curve, which is why the stresses that result in values lower than $\beta_{F}$, in the predictions of life, tend to infinity in steels.

In the current norms or codes, there are no methodologies or forms of fatigue life predictions applicable in multiaxial loadings with or without proportionality, or for loads that are completely out of phase. The lack of regulations clearly attributes the allocation of eventual types of joints to the designer; these are not evidently listed in the standards, into lower, upper, or extra classes when possible (TREMARIN; PRAVIA, 2017). The vast majority of studies in the last 70 years, focused their efforts on the analysis of proportional, phased, and uniaxial stress (TCHOUPOU, 2015).

In this study, the virtually generated stresses do not exceed $50 \%$ of the flow stress of the material at any pair of angles, because there is a possibility of rebalancing the RS in the event of plastic deformation, even if only locally.

\subsection{Goldak equation}

One of the best known three-dimensional and non-linear models used in computer simulation of heat conduction for welding processes using a mobile thermal source was presented by (ROSENTHAL, 1946) and explored by (EISAZADEH et al., 2015). This method describes a volume of material in a transient liquid state (Figure 2), which forms the weld bead when moving along the metal part. The volume must be adjusted to be as similar as possible to the volume of the fusion pool (DARMADI; KIET-TIEU; NORRISH, 2014). The model is described by Equation (3).

$Q_{\text {int }}=\mathrm{nIV}$ 
$q_{f}(x, y, z)=\frac{6 \sqrt{3} Q_{i n t}}{\pi \sqrt{\pi a b c_{f}}} \exp \left(-3 \frac{z^{2}}{b}-3 \frac{y^{2}}{a}-3 \frac{\left(x-v t_{2}\right)^{2}}{c_{f}}\right) \mathrm{p} / \mathrm{x}>0 \mathrm{~W} / \mathrm{m}^{3}$

$q_{r}(x, y, z)=\frac{6 \sqrt{3} Q_{i n t}}{\pi \sqrt{\pi a b c_{r}}} \exp \left(-3 \frac{z^{2}}{b}-3 \frac{y^{2}}{a}-3 \frac{\left(x-v t_{2}\right)^{2}}{c_{r}}\right) \mathrm{p} / \mathrm{x}<0 \mathrm{~W} / \mathrm{m}^{3}$

Precise determination of the values of $\left(a, b, c_{f}\right.$, and $\left.c_{r}\right)$, which correspond to the size of the melt pool (JOSHI et al., 1970) (Figure 2), is essential for finding the position and the size of the two main zones, FZ and HAZ, and the position of the maximum temperatures, as well as the respective distributions of the isotherms in the HAZ (BHATTI et al., 2015). In Equation (3), $v$ corresponds to the travel speed on the $x$-axis.

Figure 2 shows schematically the two ellipses that model the volume of the solid as a function on the axes $z<0$ and $z>0, x<0$ and $x>0$ and $y<0$ and $y>0$ and the intensity of the incident heat flow described in Equation (3).

In Equation (2), $n$ represents the efficiency of the process, $60 \%$ and $98 \%$, depending exclusively on the welding process, $\mathrm{I}$ is the welding current (amp), and $V$ is the welding voltage (volts).

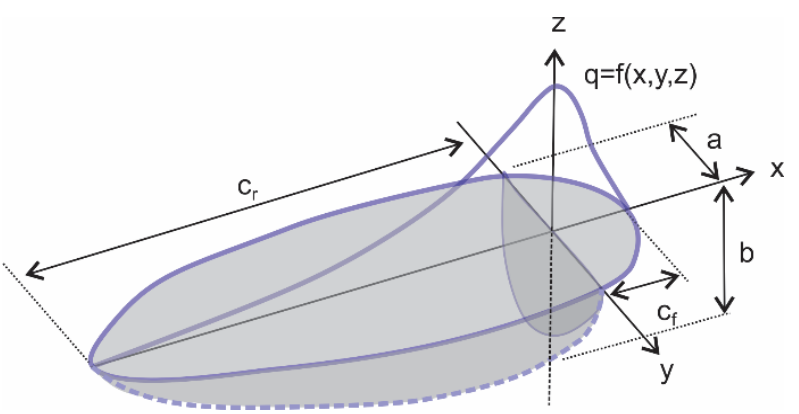

Figure 2- Schematic presentation of the two ellipses - front and rear - modelled by Equation (3). Source: Adapted (ROSENTHAL, 1946).

For Yadaiah (YADAIAH; BAG, 2014), Goldak's mathematical model achieved a considerably more accurate temperature distribution in the melting zones compared to the other available models, for example the Gauss method, in the welding process. Also, according to (YADAIAH; BAG, 2014), unlike the Gauss model, the (ROSENTHAL, 1946) model penetrates the solid. This characteristic is more suitable for mobile sources (DARMADI; KIET-TIEU; NORRISH, 2014). Especially interesting is the work of (MIKAMI; NAKAMURA; MOCHIZUKI, 2016), which carried out two simulations. In the first, the thermal source moved only on the locomotion axis (x). In the second simulation, a weaving movement (cyclic displacement perpendicular or main axis, similar to the sinusoidal curve) was inserted in addition to the displacement, in order to represent with greater fidelity the movement of the torch or electrode in the welding operation. The weaving movement did not cause significant changes to the results obtained in the first simulation.

\subsection{Thermal-mechanical properties}

Unlike the linear form of heat transfer, characteristic of some manufacturing processes, for the welding process we need to consider the evolution of the microstructures and thermomechanical properties of the materials, depending on the instantaneous temperature or the microstructural change. For the proper definition of the isotherms and the elastic and plastic deformations arising from the dilations in the $\mathrm{HAZ}$ and $\mathrm{MB}$, it is essential to define the thermomechanical properties as a function of temperature.

The values of thermomechanical properties for steel SAE 1020 (JOSHI et al., 1970) used in modeling with the finite element method are very important. The specific heat (BHATTI et al., 2015), thermal conductivity (DENG; MURAKAWA, 2006), coefficient of thermal expansion (GANNON et al., 2010) density (DENG, 2009) emissivity (SADIQ et al., 2013), Poisson's ratio (KNOEDEL; GKATZOGIANNIS; UMMENHOFER, 2017), modulus of elasticity (GANNON et al., 2010) yield stress (KRZYZANOWSKI; BEYNON, 1999), and latent heat (333 kJ/kg) (KNOEDEL; GKATZOGIANNIS; UMMENHOFER, 2017) are shown in Figure 3 at the solidus and liquidus temperatures of $1749 \mathrm{~K}$ and $1788 \mathrm{~K}$, respectively. 


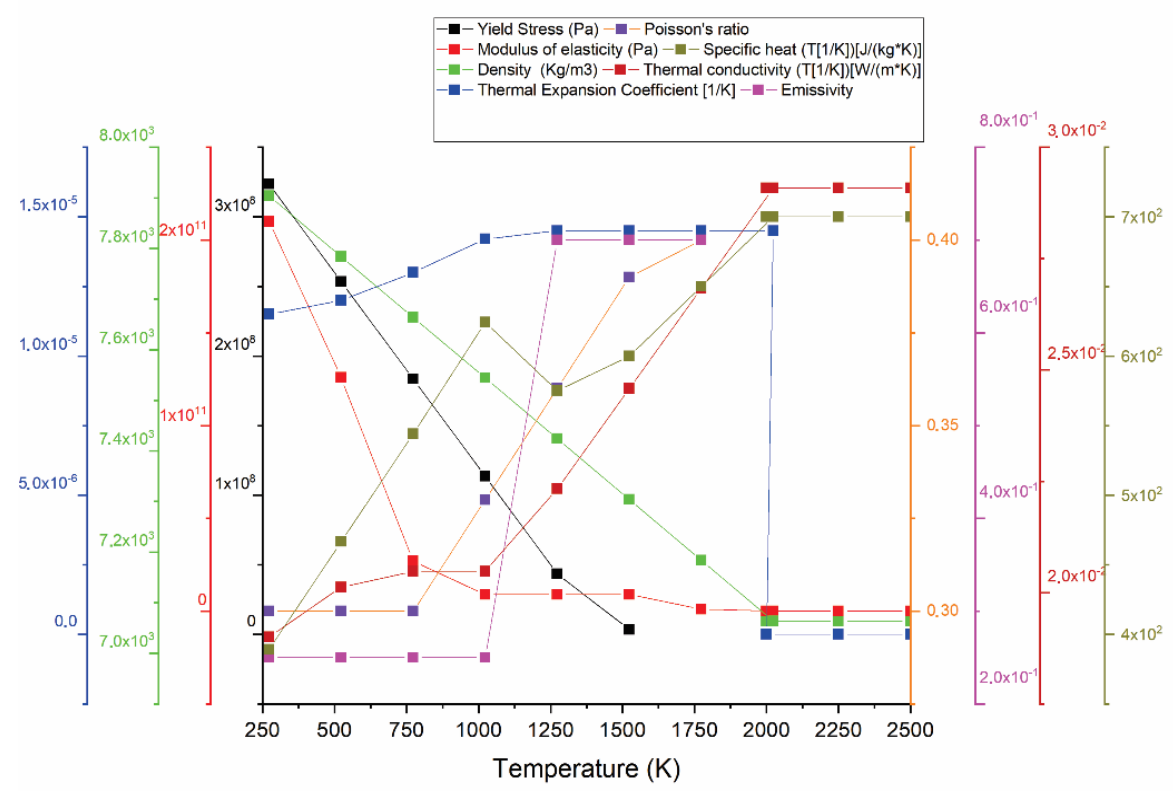

Figure 3 - Evolution of thermomechanical properties as a function of temperature for steel SAE 1020.

Figure 3 shows the temperature dependence of thermomechanical properties in the range from $273 \mathrm{~K}$ to $2500 \mathrm{~K}$. It should be noted that some properties have zero value above the temperature of $1749 \mathrm{~K}$ as a result of the melting of the material.

Simulation is considered by countless researchers as the least linear description of the welding process, having the greatest complexity in the analysis of the phenomena suitable for computer modeling (LINDGREN, 2006).

\subsection{Residual Stresses}

According to (ROSSINI et al., 2012), RS is generated in several manufacturing processes that involve at least one of the following: material deformation, heat treatment, heating, machining (HUA et al., 2005), or processing operations that allow the microstructural transformation of the material. RS originates from numerous sources and can be present in semi-industrialized raw or unprocessed material, in components with final geometry, or introduced during the last stage of manufacture.

RS is a complex quantity that is difficult to evaluate. According to (EUROCODE 3, 2005) and (BS, 2005), most fatigue life estimates do not consider the RS or overestimate it, proposing a range of values strongly linked to the component's geometry.

The RS is the result of different properties of the material in the HAZ/MB/FZ regions at high temperatures and different rates of elastic and plastic deformation. It appears as the material changes its structure to balance the forces acting on volume, resulting in micro-displacements in the solid interior.

It is therefore important to predict the effects of the thermal cycle on the metallic material during the welding process, in particular the peak temperatures in each region, the timing welding time $-t_{2}(s)$ of each peak in the thermal cycle in each region (FZ, HAZ, MB and sub-regions), and the subsequent cooling rates. Finding intensity and direction of the RS in the fatigue life predictions makes it possible to quantify the performance degradation and to characterize and relate the microstructural changes with their thermomechanical properties (NI; WAHAB, 2017).

According to (HUANG; LIU; XIE, 2013) RS consists of a set of stresses within the solid, generated during the manufacturing processes, which remain in equilibrium. These stresses are caused by non-uniform elastic or plastic deformations (EISAZADEH et al., 2015), applied stresses, or temperature variations. In the process of welding, the source of RS is the high localized heat input.

The properties of materials used in structural constructions are profoundly altered, as they can suffer distortions, reduced dimensional stability, corrosion, or even be considerably influenced by the existence of RS (ROSSINI et al., 2012).

RS plays a significant role in the durability of welded joints (LOPEZ-JAUREGI et al., 2015), (SONSINO, 2009) (GOEDEL et al., 2018), and can change the direction and speed of propagation of cracks induced by welding. The RS can be divided into elastic, plastic, thermal and transformation stress (EISAZADEH et al., 2015). 
There are many computational models of elastoplastic deformations, such as isotropic hardening, kinetic isotropic hardening, mixed isotropic hardening, tangent modulus, von Mises, Tresca, and Mohr-Coulomb, among others. In this work, we shall use the isotropic hardening model.

Equation (4) (CAPRACE et al., 2017) represents one possible mathematical model of isotropic hardening suitable for computer simulation, where $\sigma_{\mathrm{ys} 0}$ corresponds to the yield stress and $\sigma_{\mathrm{h}}(\varepsilon)$ is the plastic deformation function.

$\sigma(\varepsilon)=\sigma_{y 0}+\sigma_{h}(\varepsilon),(4)$

In Figure 4, the material behaves elastically up to the deformation of $\sigma_{y 0}=0.02$. However, from the point $\sigma_{y s 0}$ to the point $\sigma_{y s}$ the material is deformed plastically according to different curves as a function of temperature.

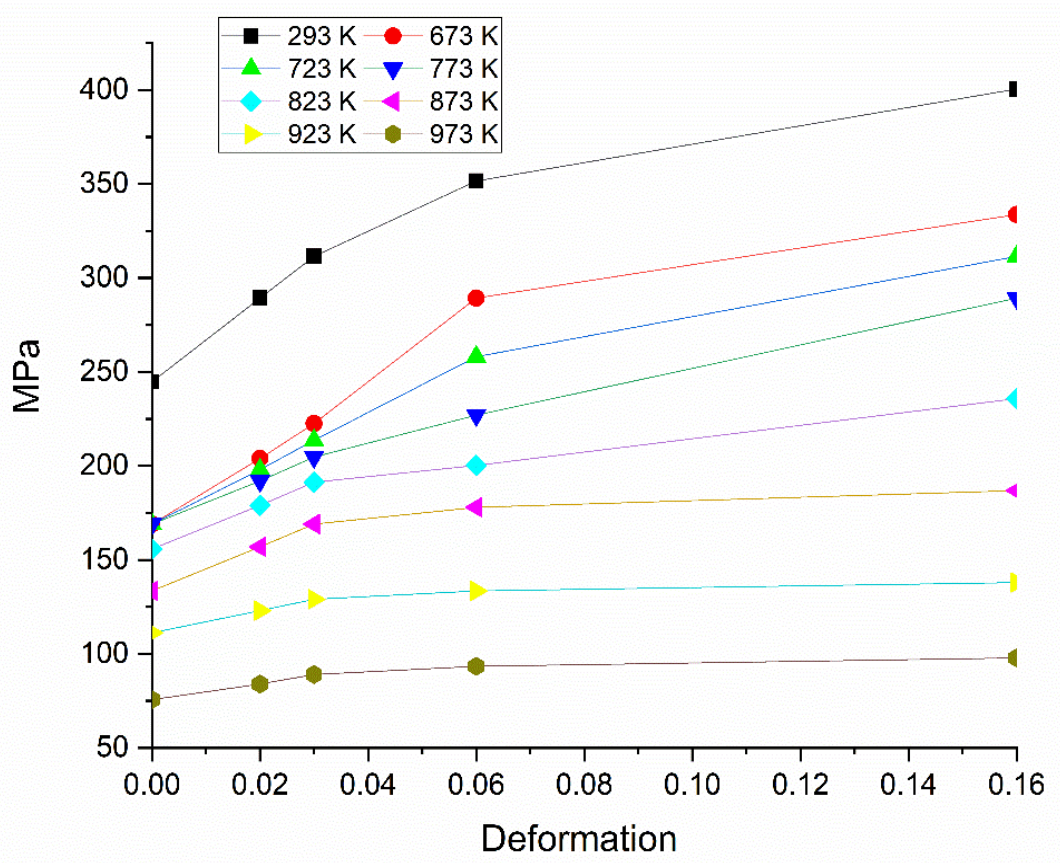

Figure 4 - Isotropic hardening curves as a function of temperature, steel SAE 1020. Source: Adapted from (SEIF; MCALLISTER, 2013).

We interpolated the values in the curves as a function of temperature because heat transfer is a continuous process.

In comparison with (HILDEBRAND; SOLTANZADEH, 2014), the present work contains a very low percentage of alloy elements, which prevents the formation of martensite. Due to the low percentage of carbon, RS from phase transformations can be disregarded in this case (CHO; KIM, 2002) and (MIKIHITO; YOSHITO, 2016) and (CAPRACE et al., 2017). However, ferrite-austenite phase transformations are implicit in the evolution of thermomechanical properties, as shown in Figure 3.

In many cases, the best approach to solving problems in engineering is to prioritize the main phenomena and to overlook the complementary analyses or insignificant factors. As mentioned in (DENG et al., 2016), the influence of phase transformations in the formation of RS in low carbon steel or low carbon alloy, or even in high strength steels, can be neglected.

In the comparative study in (CAPRACE et al., 2017), finite element method in the Sysweld ${ }^{\circledR}$ (SYSWELD, 2019) and ANSYS $^{\circledR}$ (ANSYS, 2019) software was used to determine the RS with or without coupling the influence of phase transformations and displacement restrictions during the welding processes. This study found that the biggest sources of errors are in the calibration of the model as a function of the welding parameters and thermomechanical properties, highlighting the coupling and phase transformations. Still, according to (LIU et al., 2018), computer simulations of the welding process and formation of RS using ANSYS ${ }^{\circledR}$ (ANSYS, 2019) were satisfactory, while the wrong estimates of the thermomechanical properties of the base material and process parameters of welding were again important sources of errors.

According to (JAVADI; HASANI; SADEGHI, 2015), the intensity of the RS may increase up to $16 \%$ because of displacement restrictions, which prevent the deformation of components in the welding process. This is in agreement with the previous results of (JAMES et al., 2007), who also found that the restrictions cause amplification in the formation 
of RS, and of (KOHANDEHGHAN; SERAJZADEH, 2011), who carried out component experiments on the aluminum metallic material.

The effects of RS on the fatigue phenomenon, which may increase or reduce the average stress in the fatigue cycle, are important for quantifying the influence using the Gerber or Goodman Relations models in the case of uniaxial loads. In exceptional cases, RS can even cause early fractures during the first cycles of fatigue.

Therefore, a full understanding of how the RS acts on the surface or interior of the material is an advantage from the engineering point of view, with a greater possibility of gains in fatigue phenomena controlled by stresses typical for high fatigue cycles (WITHERS; BHADESHIA, 2001).

The RS in the component, in addition to being strongly influenced by the restrictions, is closely linked to the distance from the restrictions, as shown in Figure 5.

Figure 5 can be interpreted as the RS balance since, in both $X X$ and $Y Y$ planes, the intensity of the stresses has zero-sum, as well as between the planes, which is, in this case, considered as the ZZ plane.

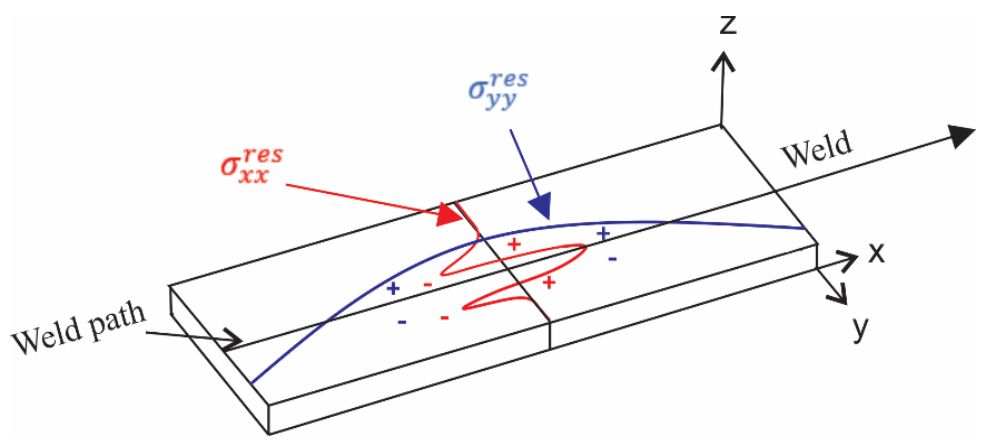

Figure 5- Representation of longitudinal $\sigma_{y y}^{r e s}$ and transversal stresses $\sigma_{x x}^{r e s}$ in segments with displacement restrictions on the upper, lower, and parallel faces of the thermal source displacement.

Thus, in addition to displacement restrictions, the position measurement of the RS is an important factor to be considered for the purpose of resolving different stress components.

\section{METHODOLOGY}

In order to determine the angles $(\Phi, \theta)$ (Figure 1) of the crack propagation plane, and determine the fatigue life prevision without the influence of RS, a generic component was subjected to a set of three-dimensional loads, with completely random non-proportional traction $\mathrm{F}(\mathrm{N})$, moment $\mathrm{M}(\mathrm{Nm})$ and shear force $\mathrm{V}(\mathrm{N})$, represented in Figure $6 \mathrm{~b})$ and c), respectively. The loads are applied to the opposite face, which is the movement face of the fusion pool, in order to represent the action of any load and its effects on any point in the structure. We used the thermomechanical properties at $298 \mathrm{~K}$ shown in Figure 3 and considered only the elastic deformations. The stresses $\tau_{n}$ and $\sigma_{n}$ in each $\mathrm{t}_{1}(\mathrm{~s})$, at points strategically positioned in the HAZ and MB, are determined from three-dimensional stresses in a computer simulation using the finite element method in the software Comsol Multiphysic, version $5.2^{\circledR}$.

The evolution of the three-dimensional stresses $\sigma_{\mathrm{x}}, \sigma_{\mathrm{y},}, \sigma_{\mathrm{z}}, \tau_{\mathrm{xy}}, \tau_{\mathrm{xz}}$ and $\tau_{\mathrm{yz}}$ obtained from the finite element method at any point is illustrated in Figure $6 \mathrm{~d}$ ). To maximize the Equation (1) by determining the best angles $(\Phi, \theta)$, we transform the function of angles $(\Phi, \theta)$ in the three-dimensional stresses in $\sigma_{\mathrm{x} \prime}, \sigma_{\mathrm{y}^{\prime}} \sigma_{\mathrm{z}^{\prime}} \tau_{\mathrm{xy}}, \tau_{\mathrm{xz}}$ and $\tau_{\mathrm{yz}}$ determining the values of the octahedral stress $\tau_{n}$ and $\sigma_{n}$.

The statistical tool in RainFlow's second uniaxial flow cannot be applied at this point to any case of uniaxial stress (BOSCO JÚNIOR, 2007) and (ASTM E 1049-85, 1985). However, we can group all the values of the change in a single set of values at time $t_{1}$, according to the method of Wang \& Brown (WANG; BROWN, 1996) illustrated in Figure 7, steps 1 and 2 . We obtain the strain values $\varepsilon_{x}, \varepsilon_{y}, \varepsilon_{z}, \gamma_{x y}, \gamma_{x z}, \gamma_{z y}$ for each set of stresses $\sigma_{x} \sigma_{y}, \sigma_{z}, \tau_{x y}$, $\tau_{x z}$ and $\tau_{y z}$ and then use the adjustment Equation (5) (WANG; BROWN, 1996),

$\varepsilon_{e q}=\frac{\sqrt{\left(\varepsilon_{x}-\varepsilon_{y}\right)^{2}+\left(\varepsilon_{y}-\varepsilon_{z}\right)^{2}+\left(\varepsilon_{z}-\varepsilon_{x}\right)^{2}+\frac{3}{2}\left(\gamma_{x y}^{2}+\gamma_{y z}^{2}+\gamma_{x z}^{2}\right)}}{\sqrt{2}(1+v)}$,

to calculate the equivalent deformation in Equation (6), 
$\varepsilon_{e q}^{r e l}=\frac{\sqrt{\left(\Delta \varepsilon_{x}-\Delta \varepsilon_{y}\right)^{2}+\left(\Delta \varepsilon_{y}-\Delta \varepsilon_{z}\right)^{2}+\left(\Delta \varepsilon_{z}-\Delta \varepsilon_{x}\right)^{2}+\frac{3}{2}\left(\Delta \gamma_{x y}^{2}+\Delta \gamma_{y z}^{2}+\Delta \gamma_{x z}^{2}\right)}}{\sqrt{2}(1+v)}$.

Finally, we use Multiaxial RainFlow, as illustrated in Figure 6e) and Figure 7 step 3. In Equation (6), the symbol $\Delta$ is the variation of the value of the chosen strain element relative to its highest value calculated in Equation (5), and $v$ is the Poisson's ratio.

We select only the pairs of strains forming the peaks and valleys of the deformations, and their respective stresses, grouped in multiples of half a cycle as in Figure 6e) and Figure 7 step 4.

The stresses corresponding to peaks and valleys of deformations are transformed in other planes until the sum of damages is maximized, as shown in Figure $6 \mathrm{~g}), \mathrm{h}$ ), and i).

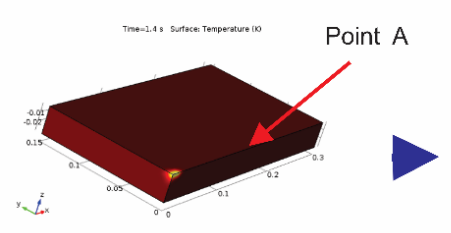

a) Welding Simulation

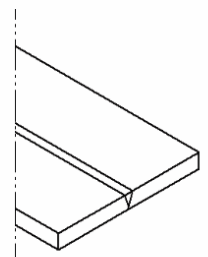

b) Component with or without simulation of the formation of welded joint

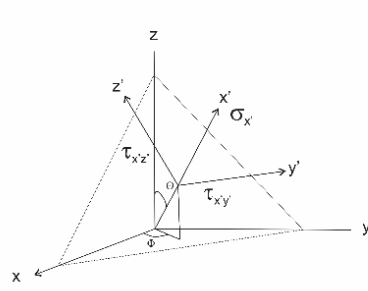

$\varepsilon_{e q}^{r e l}=\frac{\sqrt{\left(\Delta \varepsilon_{x}-\Delta \varepsilon_{y}\right)^{2}+\left(\Delta \varepsilon_{y}-\Delta \varepsilon_{z}\right)^{2}+\left(\Delta \varepsilon_{z}-\Delta \varepsilon_{x}\right)^{2}+\frac{3}{2}\left(\Delta \gamma_{x y}^{2}+\Delta \gamma_{y z}^{2}+\Delta y_{x z}^{2}\right)}}{\sqrt{2(1+v)}}$

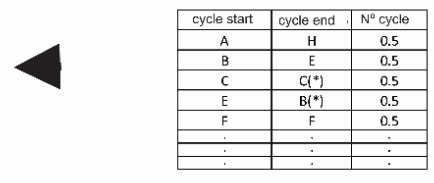

f) Simultaneous Decomposition of the values of Sigma and Tau in each row of the Rainflow table, depending on the angles of the planes (critical plane)

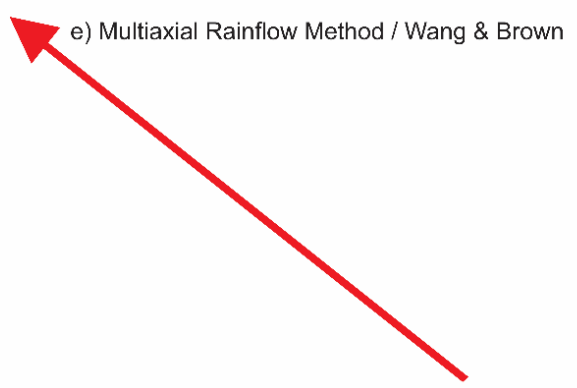

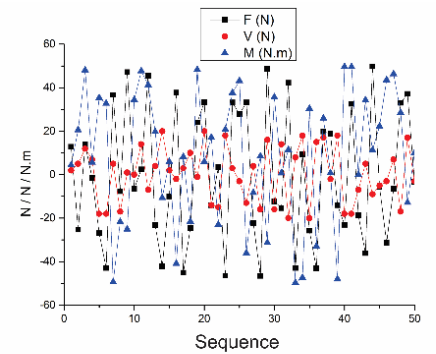

c) Variation of Efforts

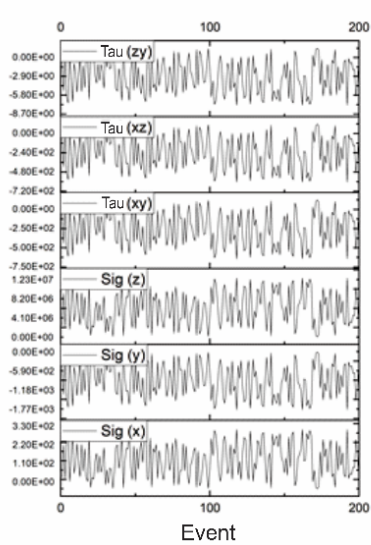

d) Sigma and Tau values in different cycles

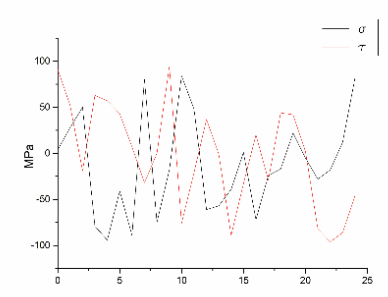

g) Tau and Sigma values (in the plane)

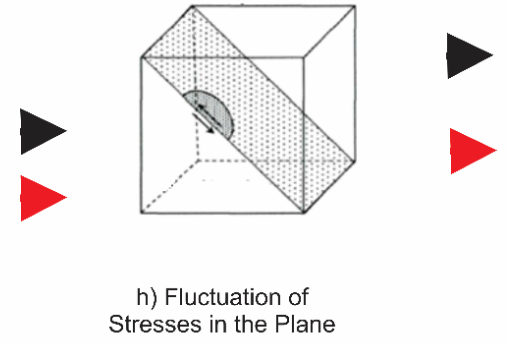

$\max \left(\tau_{a}(\Phi, \theta)+k_{f} \max \sigma_{n}(\Phi, \theta)\right)=\tau_{f}^{*}(2 N)^{b}$

$D=\sum_{i}^{m} d_{j}=\sum_{i}^{m} \frac{n_{j}}{N_{j}} \geq D_{P M}$

i) Fiedley equation and Calculation of Sum of Damage

Figure 6 - Flow of advanced steps for determination of the critical plane with RS. 


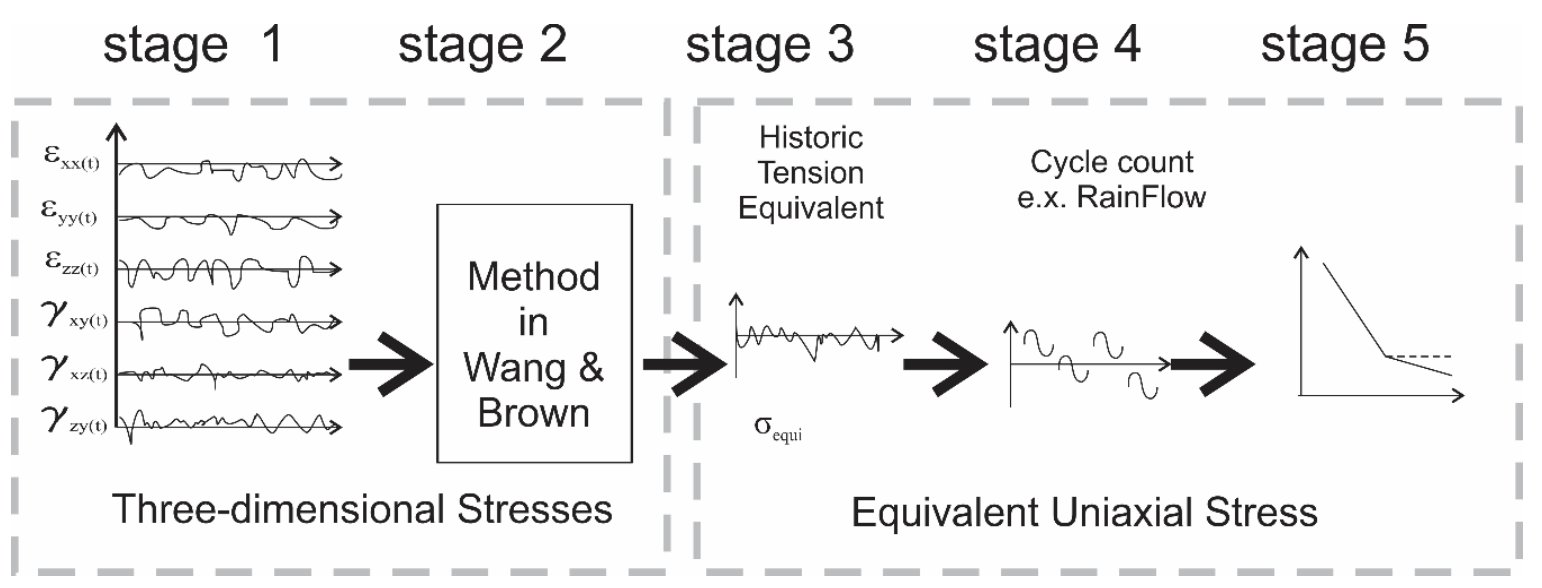

Figure 7 - Schematic illustration of the Wang \& Brown method. Source: adapted (WANG; BROWN, 1996)

The last operation performed in the system is represented by the algorithm between steps f), g), h), and i) in Figure 6 (only the arrows in red color), which illustrates the execution of the solver function in any calculation spreadsheet. The solver function varies $\Phi$ from 0 to $90 \cong$ and $\theta$ from 0 to 90 ㅇmultaneously, looking for the combination that maximizes the damage calculated by Equation (1) and Palmgren-Miner Equation, Figure 6i). For each pair of angles, it calculates and adds the damages, finding the shortest fatigue life using only the properties of the materials under multiaxial fatigue test, shown in Table 1.

The second sequence, illustrated in Figure 6a), simulates the movement of the thermal source, starting with the blue arrow in Figure 6, obtaining the evolution of temperature and RS at each time $t_{2}(s)$, with thermomechanical properties (Figure 3, Figure 4) taken into account. The boundary conditions of Figure $\mathbf{8}$ were obtained in the same virtual positions as the extraction of three-dimensional stresses. The positions were strategically allocated at predetermined points in the HAZ and MB, as shown in Figure 9, with the direction of displacement of the thermal source parallel to the $\mathrm{x}$-axis, similar to Figure 2 , to obtain the values $\sigma_{x T R}, \sigma_{y T R}, \sigma_{z T R} \tau_{x y T R,} \tau_{x z T R}$ and $\tau_{y z T R}$.

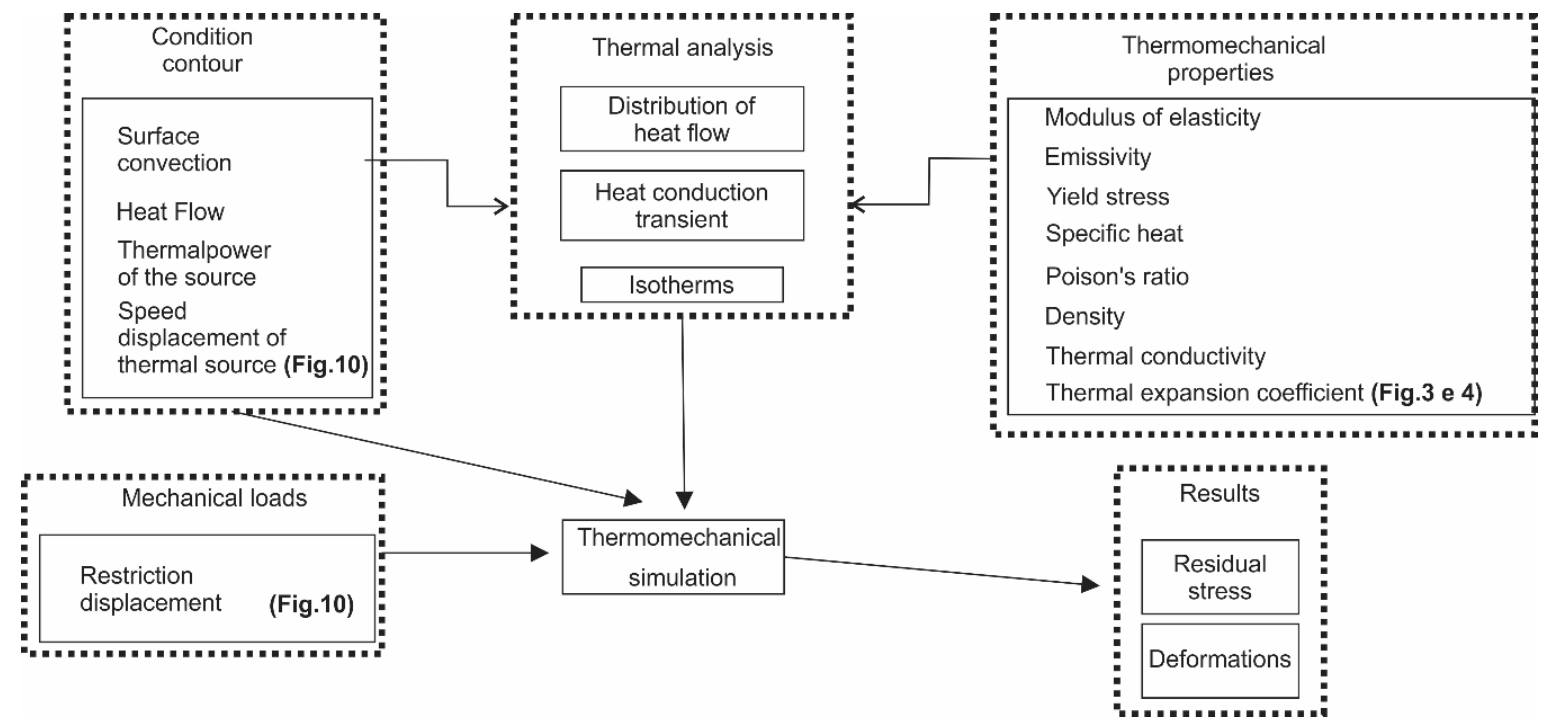

Figure 8 - Flow chart of the simulation of residual stress formation. Source: Adapted (SRIVASTAVA et al., 2017)

The events described in Figure 8 are details Figure 6a). We imposed the displacement restriction on the finite element mesh nodes on the face perpendicular to the displacement face of the fusion pool, with the restriction on the deformations arising from welding, as shown in Figure 10.

Figure 8 schematically shows the information and correlation flow during the computer simulation under the boundary conditions represented in Figure 9 and Figure 10a) and b).

It is important to note that the successive points in Figure 9 are separated in the $Y$ direction by $2.5 \mathrm{~mm}$ and in the $Z$ direction by $1.25 \mathrm{~mm}$. This difference is the result of the study's focus on the thermal and mechanical influence on the $\mathrm{HAZ}$ and MB. 


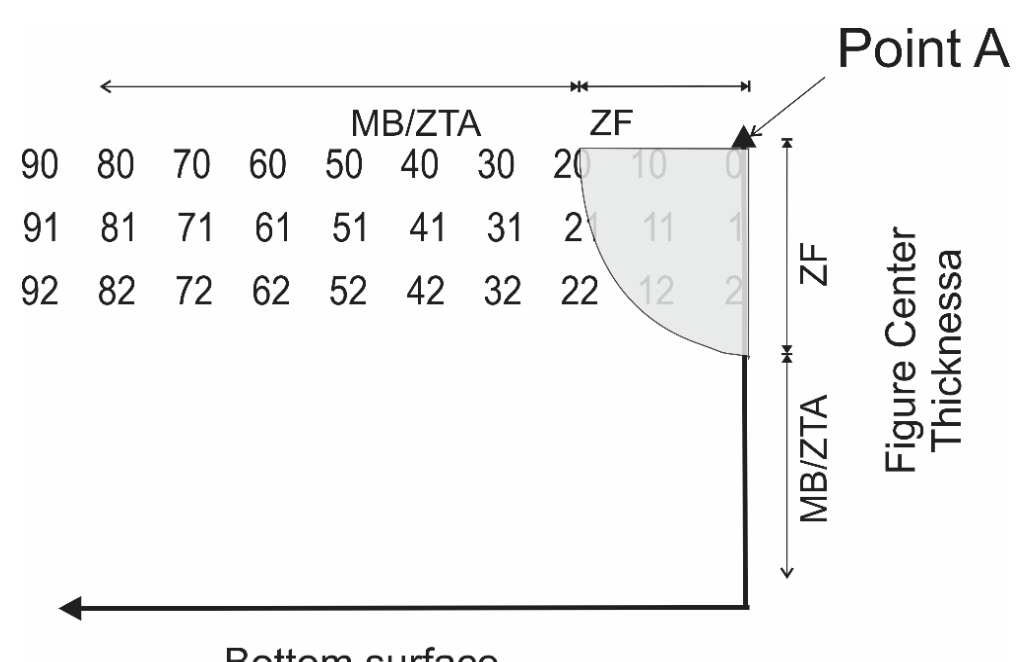

Figure 9- Reference points and point $A$, broken in both directions from position 0.

Figure 10a), b) shows the thermal and mechanical boundary conditions, respectively. Doing several simulations based in results convergence authors decided choice the tetragonal element, for the computer simulation of the welding process, with dimensions varying between 1.25 and $2.5 \mathrm{~mm}$, without chamfer, illustrated in Figure 6 a) and Figure 10a), b).

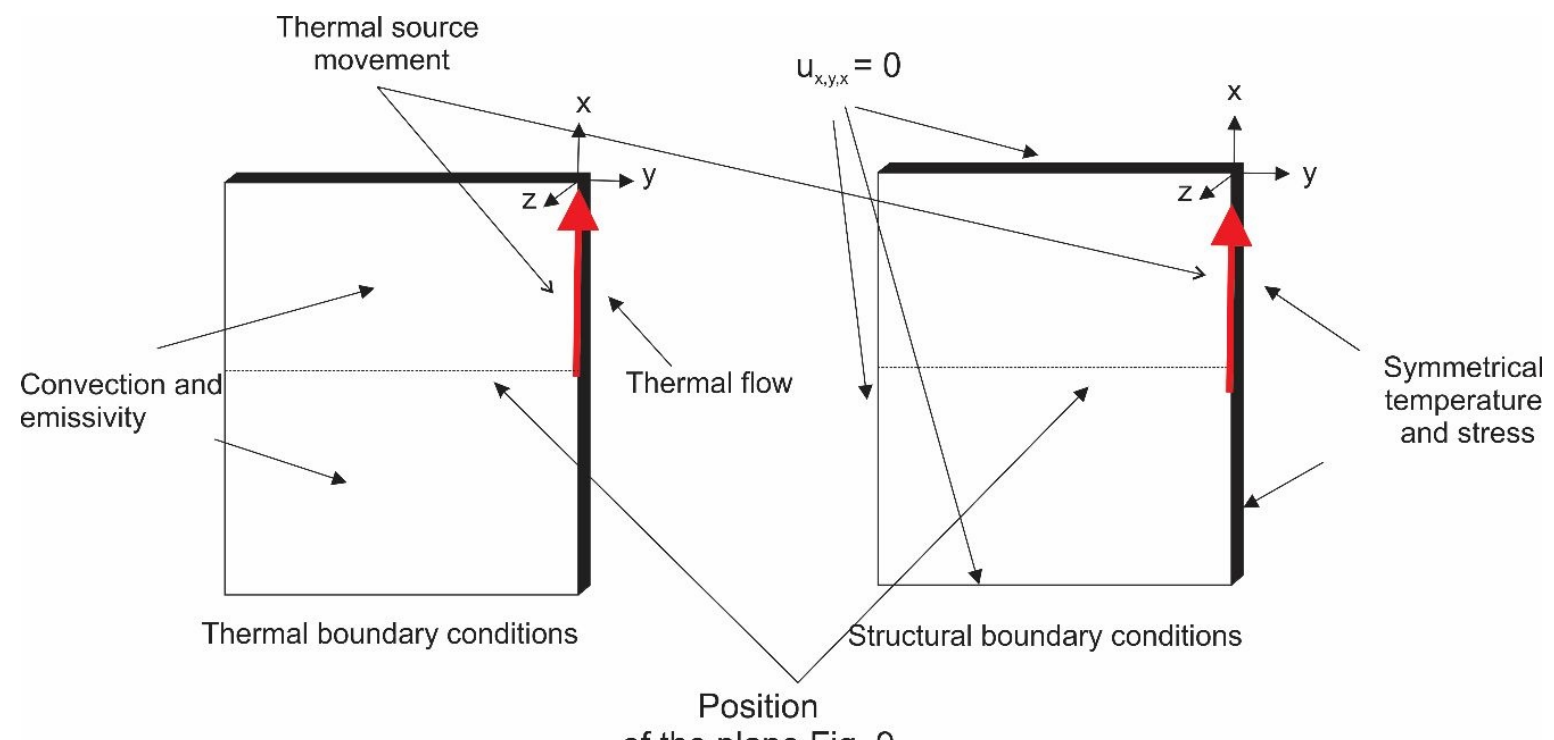

a)

of the plane Fig. 9

b)

Figure 10 - Boundary conditions thermomechanical simulation of the welding process. a) thermal boundary conditions mirrored by symmetry, b) mechanical boundary conditions mirrored by symmetry. Source: Adapted (SERINDAG et al., 2017)

In Figure 6, there are two complete simulation flows in which the values of RS and thermal cycles obtained in step a) occur or do not occur. In the flow described by the blue arrow in Figure 6, we would only be analyzing the influence of RS, completely excluding all other possible variations.

This method can be applied in any position in the HAZ / MB / FZ, mainly on the surface of the solid. In addition to discovering the angles at which crack propagation occurs, it will be possible to determine the location of the first crack, and the reduction in fatigue life.

Finally, all steps are repeated to determine the influence of welding and the source movement on the RS $\sigma_{x T R,} \sigma_{y T R,} \sigma_{z T R,} \tau_{x y T R}, \tau_{x z T R}$ e $\tau_{y z T R}$ at $\mathrm{t}_{(2)}$. These stresses are subsequently aggregated according to (AHLSTRÖM, 2016) and (SRIVASTAVA et al., 2017) to obtain the stresses $\sigma_{x} \sigma_{y}, \sigma_{z}, \tau_{x y} \tau_{x z}$ and $\tau_{y z}$, and redoing all calculations determines new angles and new projections of life in fatigue. 
There is no consensus in the literature regarding the exact time $t_{2}(s)$ of the computer simulation for the acquisition of RS. In this work, we only consider the values of RS obtained in time $t_{2}(s)=86400$ seconds. This time represents $24 \mathrm{~h}$ after the execution of the welding process. To reduce processing time, we opted to carry out all simulations with half of the component as a mirrored image of the other half, without losing the representativeness of the data, as shown in Figure 9, Figure 10 and Figure 11.

We performed only a computer simulation with 85686 tetrahedral elements, where the domain was segmented into two subdomains, as shown in Figure 11. The first subdomain had 74141 elements, and the second subdomain had 11545 elements, so that the system contained in total 379582 degrees of freedom and 6603108 different equations. The simulation of structural analysis is performed simultaneously with thermal analysis. Both simulations are non-linear, generating isotherms, micro deformations, and RS, mainly in the first domain. Both simulations were performed using the Comsol Multiphysics software, version 5.2, with the aid of the MUMPS - Multifrontal Massively Parallel Solver method to solve non-linear equations during 64 hours of simulation of the welding process in 86400 seconds. A surface, positioned perpendicular to the displacement of the thermal source, with pre-positioned points, separated by $2.5 \mathrm{~mm}$ from each other in the $y$-direction and $1.25 \mathrm{~mm}$ in the z-direction, as shown in Figure 9, is virtually inserted in the solid.

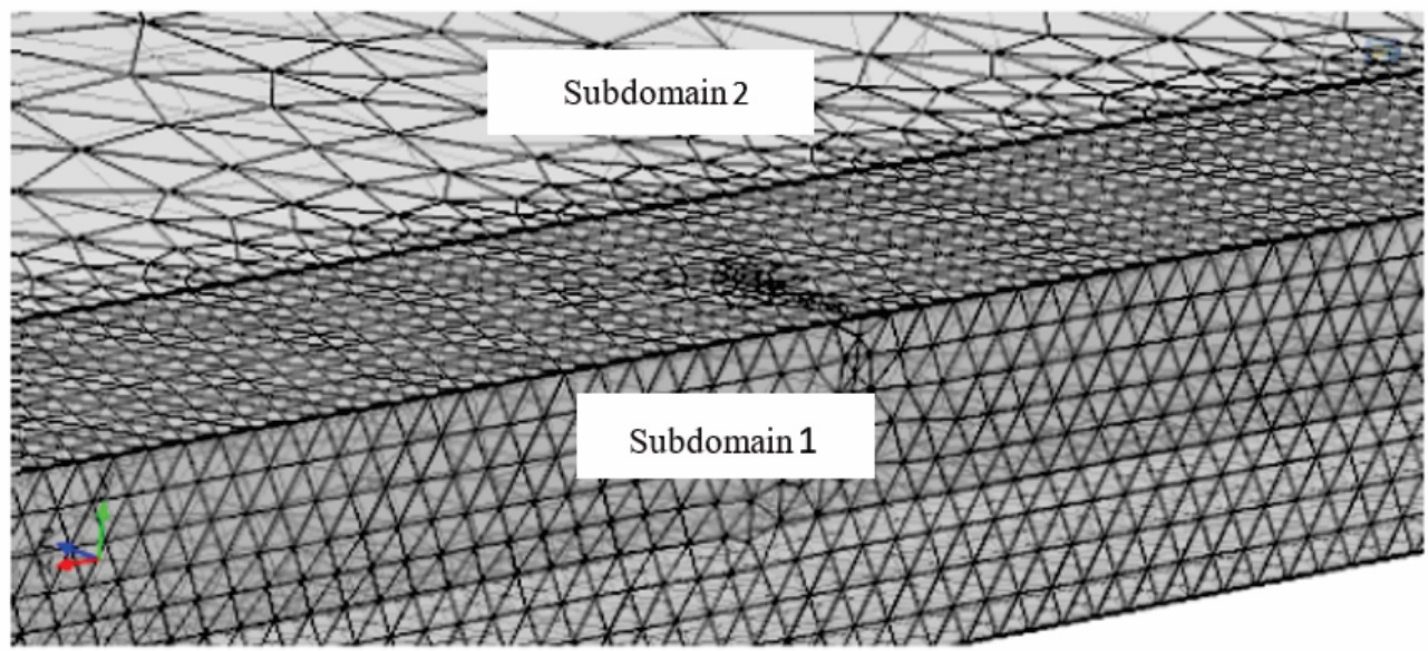

Figure 11 - Representative image of virtual elements, with necessary refinement in subdomain 1, referring to the position of the virtual board, Figure 9.

Table 1 - Process characteristics, dimensions of the melting pool and material properties, steel SAE 1020.

\begin{tabular}{|c|c|c|c|c|c|}
\hline Property & Value & Unit & Property & Value & Unit \\
\hline Current & 150 & A & $\begin{array}{l}\text { Liquidus } \\
\text { temperature }\end{array}$ & 1749 & Kelvin \\
\hline Tension & 30 & V & $\mathrm{k}_{\mathrm{f}}$ & 0.412 & No unit \\
\hline Speed & 6 & $\mathrm{~mm} / \mathrm{s}$ & b (exponent) & 0.099 & No unit \\
\hline Efficiency & $0.7(70 \%)$ & No unit & Constant $\tau_{f}^{*}$ & 1917 & $\mathrm{MPa}$ \\
\hline Convection coefficient & 15 & $\mathrm{~W} /\left(\mathrm{m}^{2} \mathrm{~K}\right)$ & $\begin{array}{l}\text { Poisson coefficient, } \\
\text { room temperature }\end{array}$ & 0.33 & No unit \\
\hline $\begin{array}{l}\text { Latent heat of } \mathrm{L} / \mathrm{S} \text { phase } \\
\text { transformation }\end{array}$ & 333 & $\mathrm{~kJ} / \mathrm{kg}$ & $\begin{array}{l}\text { Heat capacity, room } \\
\text { temperature }\end{array}$ & 389 & $(\mathrm{~T}[1 / \mathrm{K}])[\mathrm{J} /(\mathrm{kgK})]$ \\
\hline Room temperature & 298 & Kelvin & $\begin{array}{l}\text { Thermal expansion } \\
\text { coefficient, room } \\
\text { temperature }\end{array}$ & $1.2310^{-5}$ & {$[1 / K]$} \\
\hline Preheating Temperature & 308 & Kelvin & $\mathrm{a}$ & 5.22 & $\mathrm{~mm}$ \\
\hline Power Thermal source & 3150 & W & $b$ & 2.95 & $\mathrm{~mm}$ \\
\hline Steel density & 7850 & $\mathrm{Kg} / \mathrm{m}^{3}$ & $c_{f}$ & 9 & $\mathrm{~mm}$ \\
\hline $\begin{array}{l}\text { Modulus of elasticity, } \\
\text { room temperature }\end{array}$ & 210 & $\mathrm{GPa}$ & $\mathrm{c}_{\mathrm{r}}$ & 17.7 & $\mathrm{~mm}$ \\
\hline $\begin{array}{l}\text { Thermal conductivity, } \\
\text { room temperature }\end{array}$ & 19 & $(T[1 / K])[W /(m K)]$ & Solidus temperature & 1787 & Kelvin \\
\hline
\end{tabular}


Figure 11 shows the refinement of the mesh at the place of insertion of the perpendicular plane (Figure 9). This refinement is necessary since in this place temperature and RTs will be calculated, thus requiring the construction of a more refined mesh.

\section{RESULTS}

Figure 12 presents the results of the computer simulation of the welding process. The sequence of figures represents the evolution of temperature in time $\left(t_{2}\right)$. The isotherms due to the mobile, continuous, three-dimensional thermal source show the evolution during times $t_{2}(s)$ of $0,1,5,35,200$, and $400 \mathrm{~s}$.
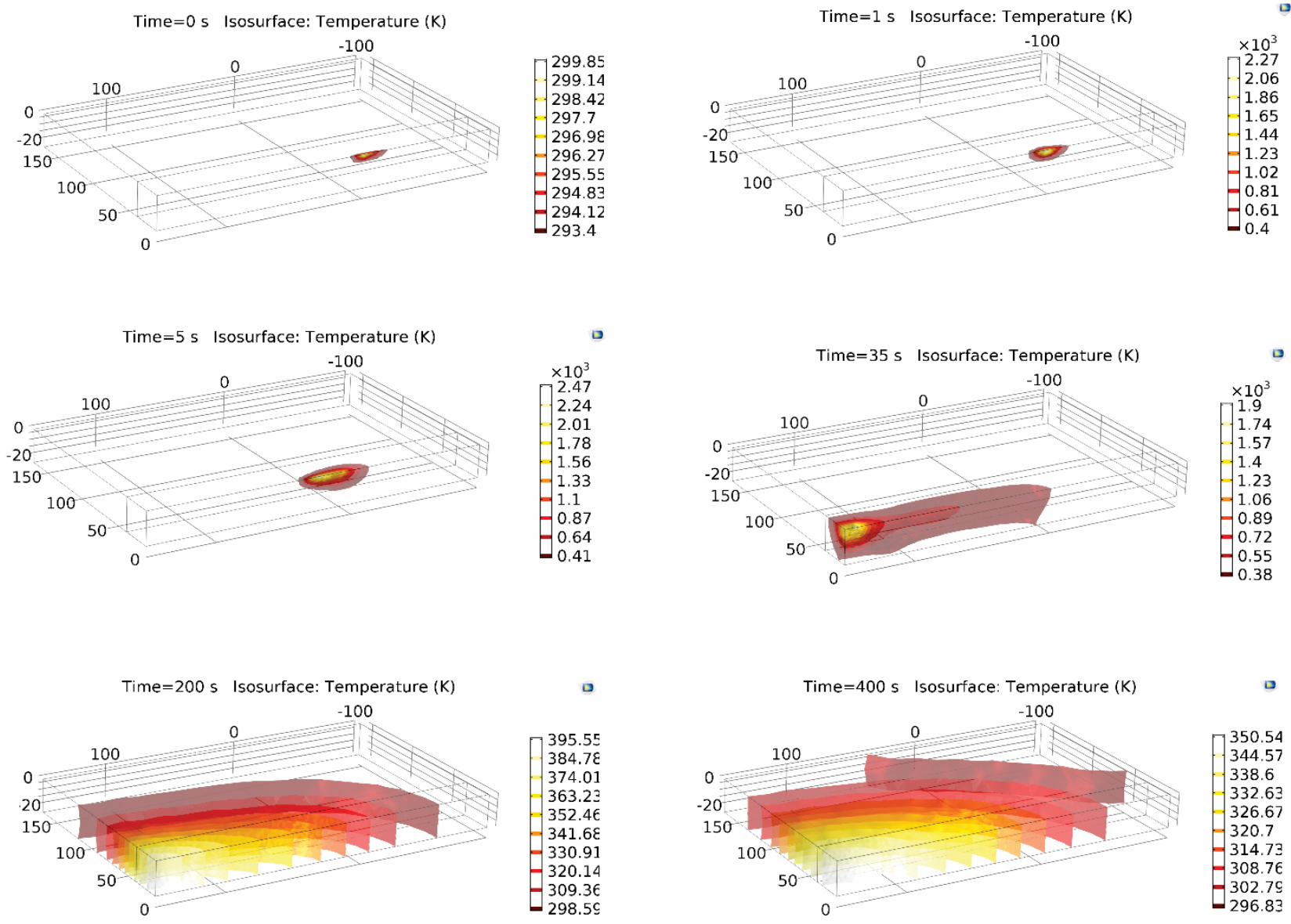

Figure 12 - The evolution of the isotherms due to the thermal source in movement. The times $t_{2}(s)$ are $0,1,5,35,200$, and 400 s. On the right is the Kelvin temperature bar.

At time $t_{2}(s)=5 \mathrm{~s}$, the thermal source is completely inside the solid, and the temperature reaches $2450 \mathrm{~K}$, in the center of the melt pool, a result very similar to other studies. At time $t_{2}(\mathrm{~s})=35 \mathrm{~s}$, the thermal source is not completely inside the solid any longer, and there is a significant reduction in temperature, again agreeing with the results from other studies, for example (SHEN et al., 2017) and (DARMADI; KIET-TIEU; NORRISH, 2014).

Figure 13 shows the temperature profile projected in the virtual internal plane (YZ) perpendicular to the movement of the thermal source positioned in the center of the component similarly to Figure 9, at times $t_{2}$ (s) equal to $2,4,6$, and $10 \mathrm{~s}$. 

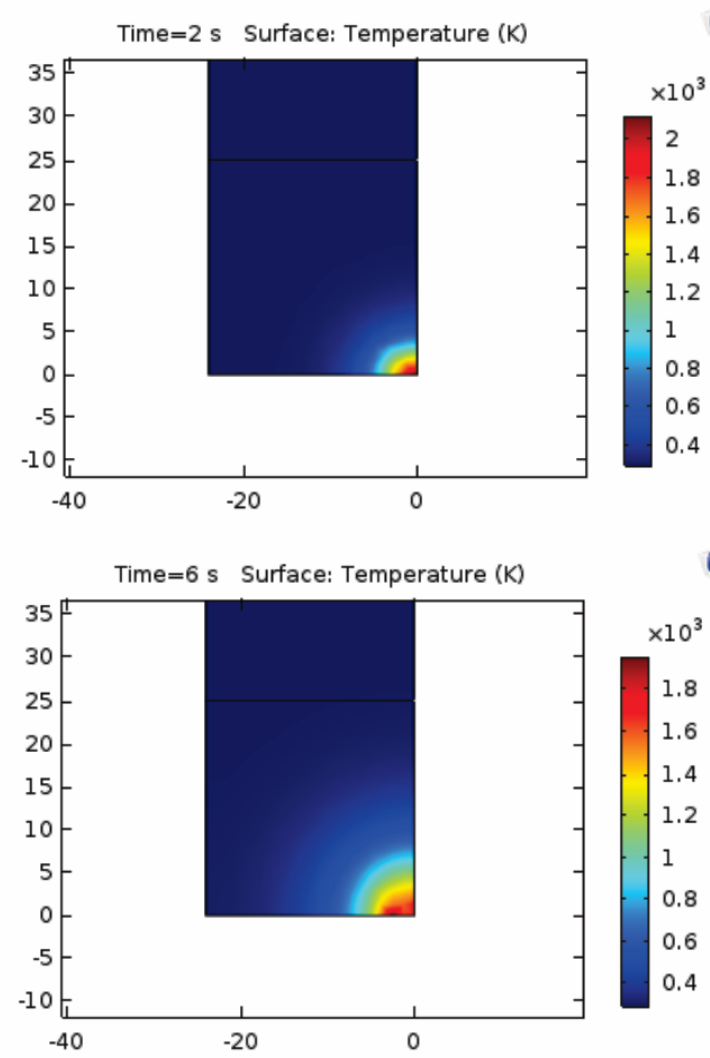

口

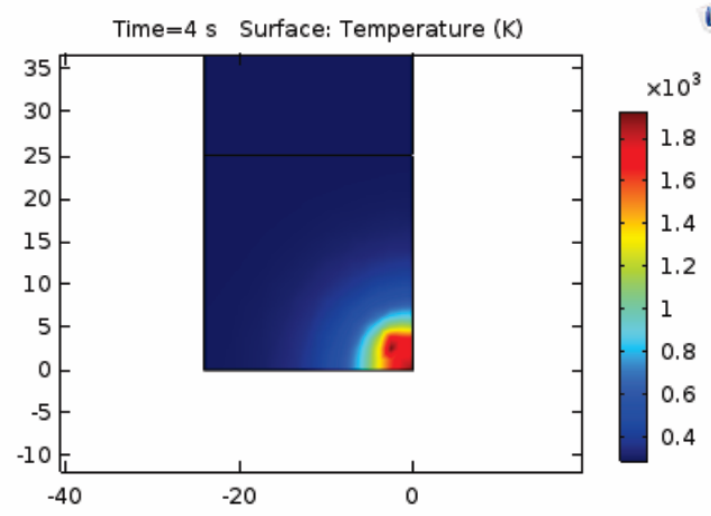

$\square$

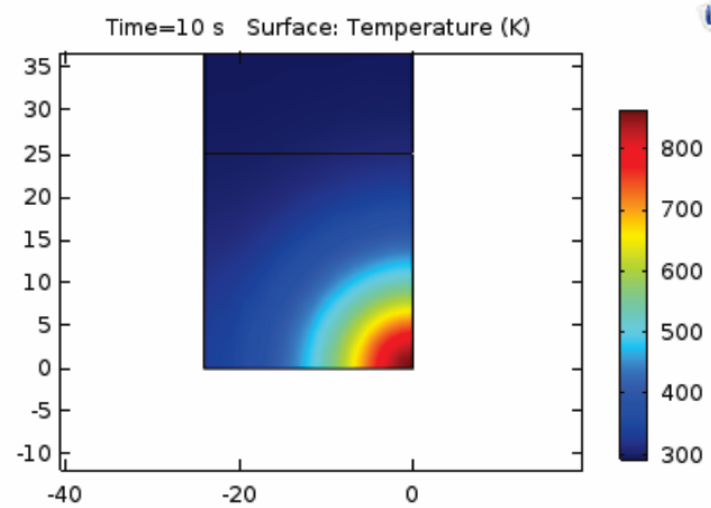

Figure 13 - Illustration of a plane (Figure 9) perpendicular to the displacement trajectory of the thermal source positioned in the center of the fusion pool component through the plate, at time t2 (s) equal to 2, 4, 6 and $10 \mathrm{~s}$. On the right is the Kelvin temperature bar.

In Figure 13, at the time $t_{2}(s)=2 s$ after reaching the plate, that the temperature reached approximately $2600 \mathrm{~K}$. After the thermal source $t_{2}(\mathrm{~s})$ increased to $10 \mathrm{~s}$, temperature decreased, reaching approximately $800 \mathrm{~K}$. Figure 14 shows thermal cycles of successive virtual points, spaced on the surface of the solid $2.5 \mathrm{~mm}$ apart in the direction of the Y-axis and $1.25 \mathrm{~mm}$ in the direction of the Z-axis, starting from the center of the fusion pool.

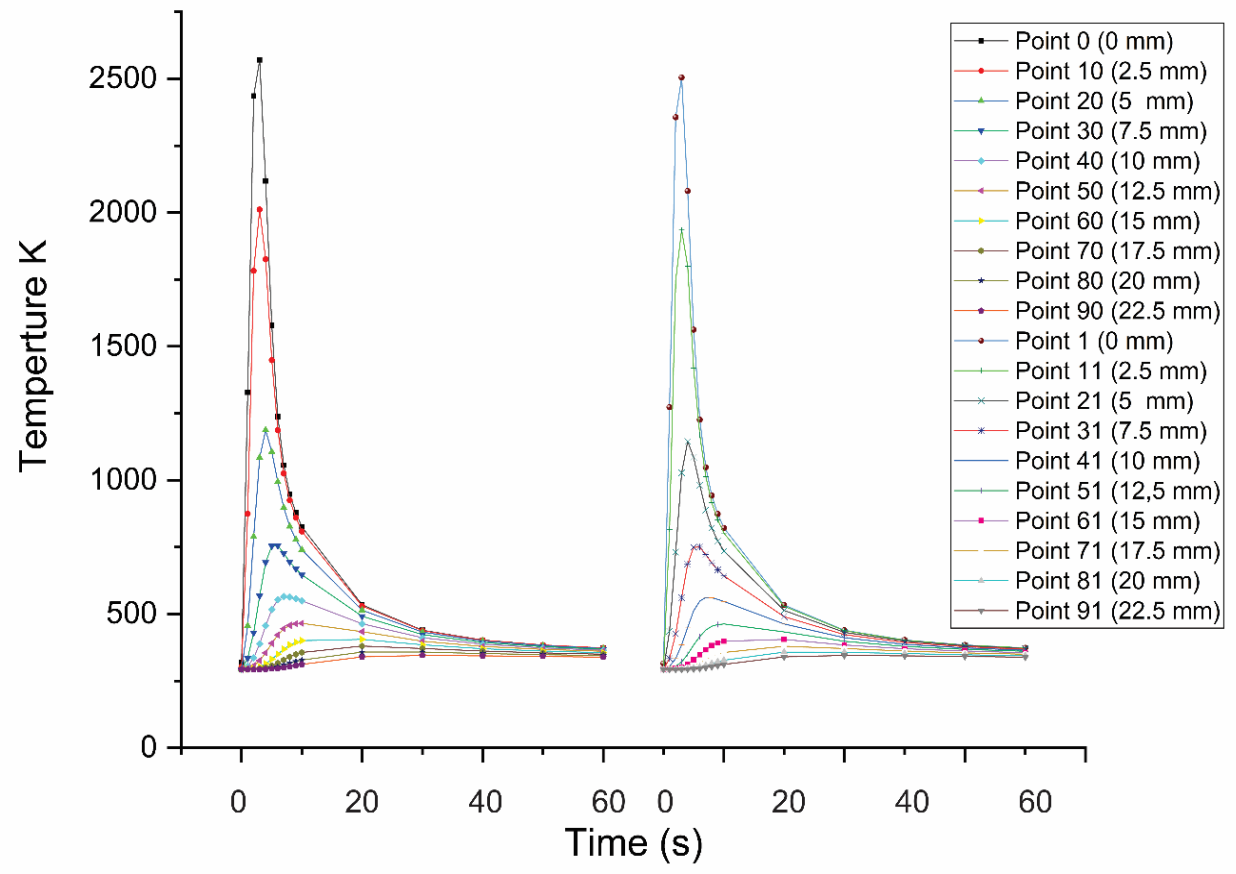

Figure 14 - Evolution of the virtual Kelvin temperature from the center of the fusion pool, at successive points spaced $2.5 \mathrm{~mm}$ apart, referred to in Figure 9. 
In Figure 14, it is clear that points 0 and 1 (at $0 \mathrm{~mm}$ ) and 10 and 11 to (at $2.5 \mathrm{~mm}$ ) in the center of the melting pool reached the melting temperature $1749 \mathrm{~K}$ of the material - solidus temperature. However, the distant points, which are the main objects of our study, did not reach the temperature of fusion. Thus, all points between $5 \mathrm{~mm}$ and $22.5 \mathrm{~mm}$ from the center of the fusion pool did not undergo significant metallurgical changes characteristic of the HAZ. Nevertheless, we will analyze all points for the RS, because RS can present effects in regions relatively distant from the classic HAZ. In addition to the significant difference in the maximum values of temperature reached by each analyzed point, we found that different points had different cooling rates, with the points closest to FZ having higher cooling rates. Such variation explains the differences in mechanical properties between different points next to the HAZ since in Figure $\mathbf{3}$ and Figure $\mathbf{4}$, differences in thermomechanical properties are considerable.

Figure 15 shows the 3D projection of the simultaneous maximum temperature in several planes (YZ) perpendicular to the displacement of the thermal source. Note that, like in Figure 14, at the points on the surface (this figure is under the $Y$-axis), there is a significant variation of temperature demarcating the regions of $F Z, H A Z$, and MB.

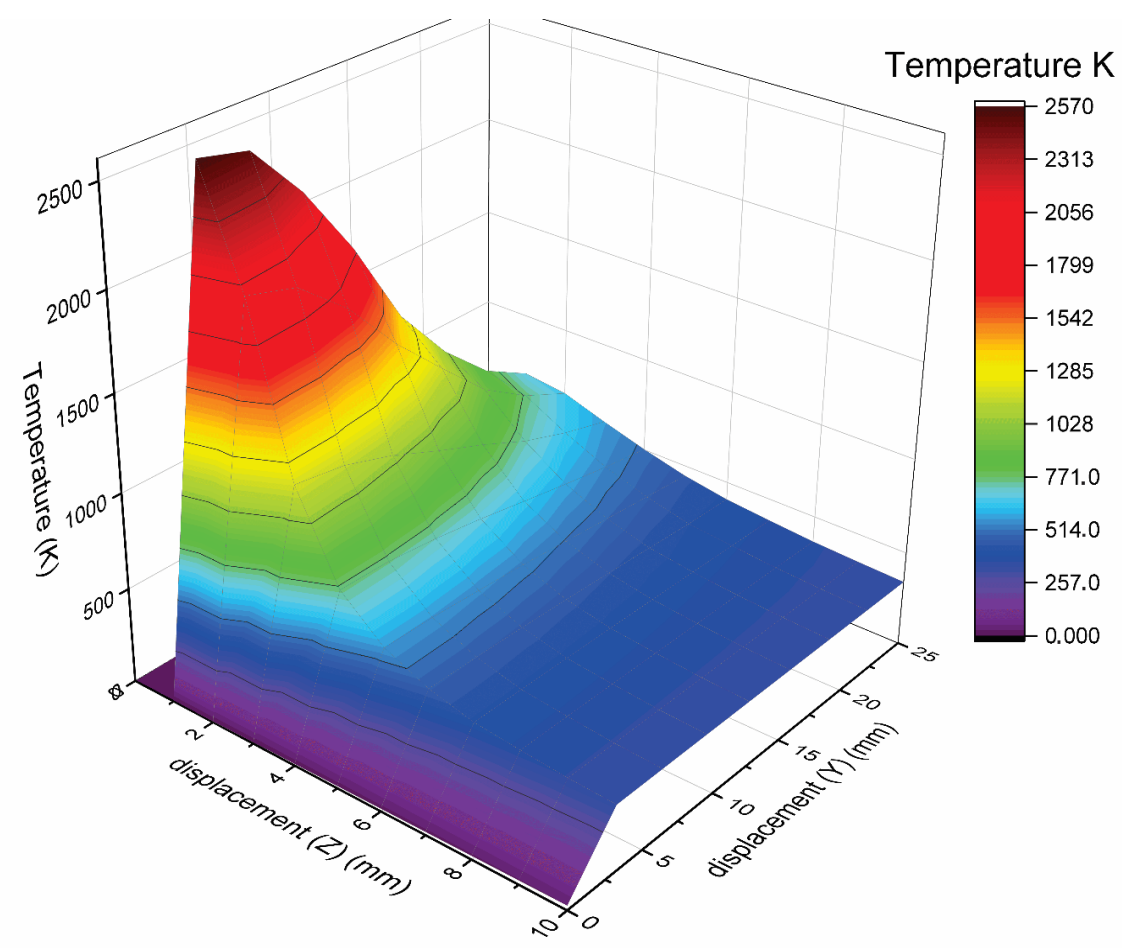

Figure 15- 3D plot simultaneously correlating the maximum temperature $K$, and the position of the respective displacements on the $\mathrm{Y}$-axis (surface of the solid) and on the Z-axis (into the solid).

In Figure 15, the instantaneous maximum value of the thermal cycle (at $t_{2}(s)$ ) isn't important, only the maximum value of temperature. The graph clearly delimits the FZ and the HAZ, since only the points with simultaneous displacements along $Y$ and $Z$ axis of less than approximately $5 \mathrm{~mm}$ are in the $F Z$, while the points positioned simultaneously between approximately $5 \mathrm{~mm}$ and $7.5 \mathrm{~mm}$ are in the classic HAZ. The points with coordinates greater than $7.5 \mathrm{~mm}$, despite not being in the HAZ, are influenced by the RS formed in the vicinity. Figure 16 shows the RS at the time $t_{2}(s)=86400 \mathrm{~s}$ on the $x, y, z$ and $x y, x z$, and $z y$ axes, for the consecutive spacing of $2.5 \mathrm{~mm}$ on the solid surface exactly aligned with the middle of the component (as illustrated in Figure 10). Knowledge of this dependence allows the maximization of the expression for the RS, as explained in Figure $\mathbf{5}$. 


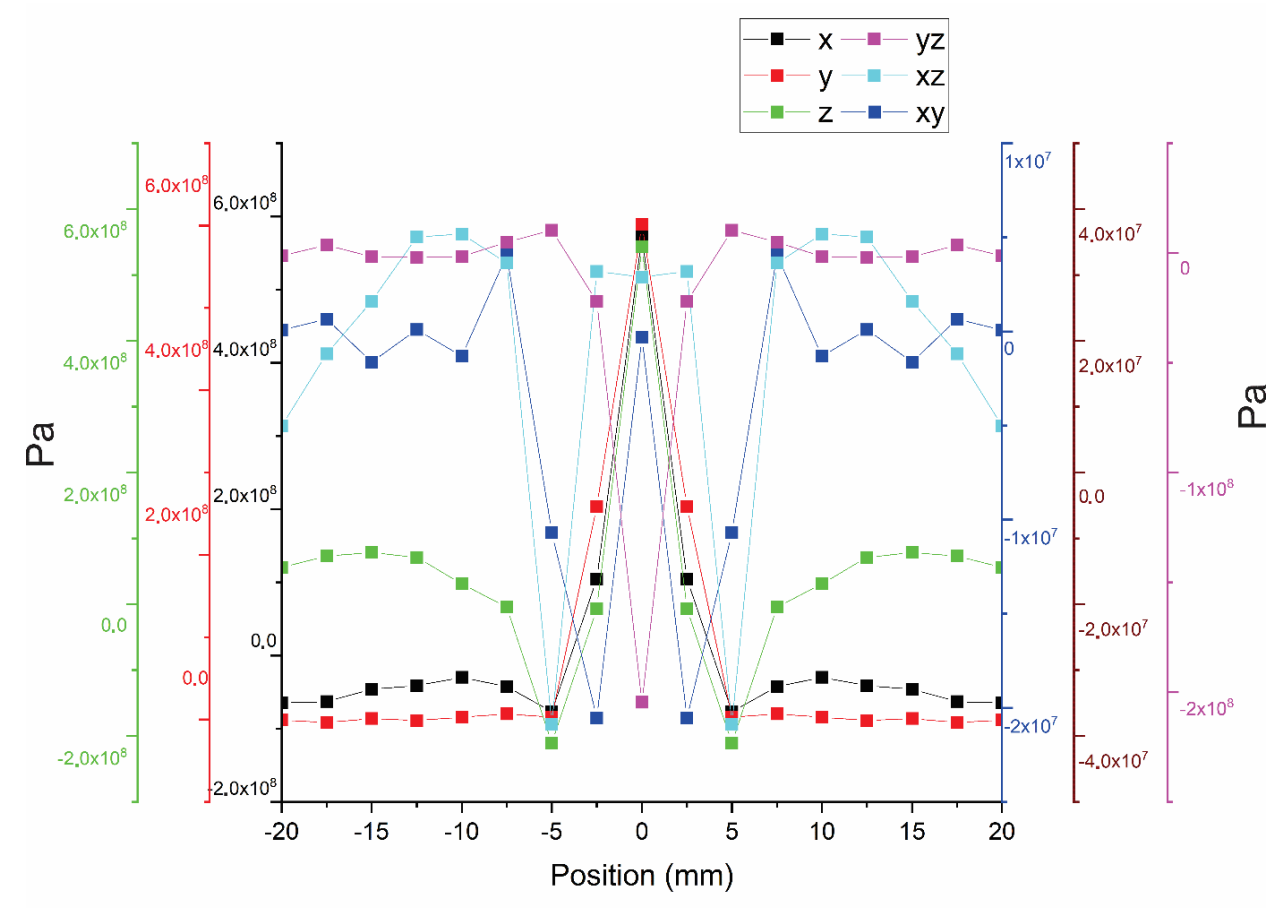

Figure 16 - Surface values of the residual stress $(\mathrm{Pa}) \tau_{\mathrm{TR}}, \sigma_{\mathrm{TR}}$ in each vector at the successive points from the center of the melt pool, $2.5 \mathrm{~mm}$ apart from each other (references $0,1,2,3,4,5,6,7,8$, and 9 in Figure 9), $\mathrm{t}_{2}(\mathrm{~s})=86400 \mathrm{~s}$.

A careful analysis of the behavior of the RS curves in the various vectors in Figure 16 reveals that at the points in the FZ from 0 to $2.5 \mathrm{~mm}$, there are significant changes in the stress, in some cases even with a change of direction. The points located between 2.5 and $5 \mathrm{~mm}$ now maintain the trend observed in the points between 0 and $2.5 \mathrm{~mm}$, and stabilize the variation vectors $x, y, y z$, or reverse the trends for the vectors $z, x z, x y$ and $z$.

Notably, any changes in position, whether along the $x$-axis or z-axis, will result in significant changes that cannot be disregarded, as shown in Figure 17, in which we present, in a three-dimensional format, the change of RS along the $Z$ vector due to the displacement along the $Z$ and $Y$ axes.

Again it is important to note that the measurement of the position of the RS in relation to the component geometry is extremely important due to the imposed restrictions and the balance of the RS in 3D space. In this particular case, all measurements of RS were performed in the center of a parallelepiped component, as shown in Figure 10.

In Figure 17, the evolution of RS is shown only in the Z plane for the points referenced in Figure 9. We note that the vast majority of the points have values very close to the value of $100 \mathrm{MPa}$, with the exception of the points in the $\mathrm{FZ}$ and $\mathrm{HAZ}$, which have positive (traction) and negative (compression) values.

In Figure 17 and Figure 18 shows the evolution of RS in the $Y$ plane. The vast majority of points do not present any values of RS, except in FZ and HAZ, where the values are positive. The Figure $\mathbf{1 9}$ shows similar behavior value of RS in $\mathrm{FZ}$ and HAZ is immensely larger than elsewhere on the $X$ plane.

When comparing Figure 17, Figure 18 and Figure 19 with Figure 16 it is extremely important to point out that in Figure 16 only the values of the surface points are presented, whereas in the 3D graphs, points inside the solid are predominant. In a systemic analysis of 3D images, it is agreed that the oscillations in the $\mathrm{X}, \mathrm{Y}$, or $\mathrm{Z}$ planes are in the $\mathrm{FZ}$ and $\mathrm{HAZ}$ and tend to decrease due to the distance. 


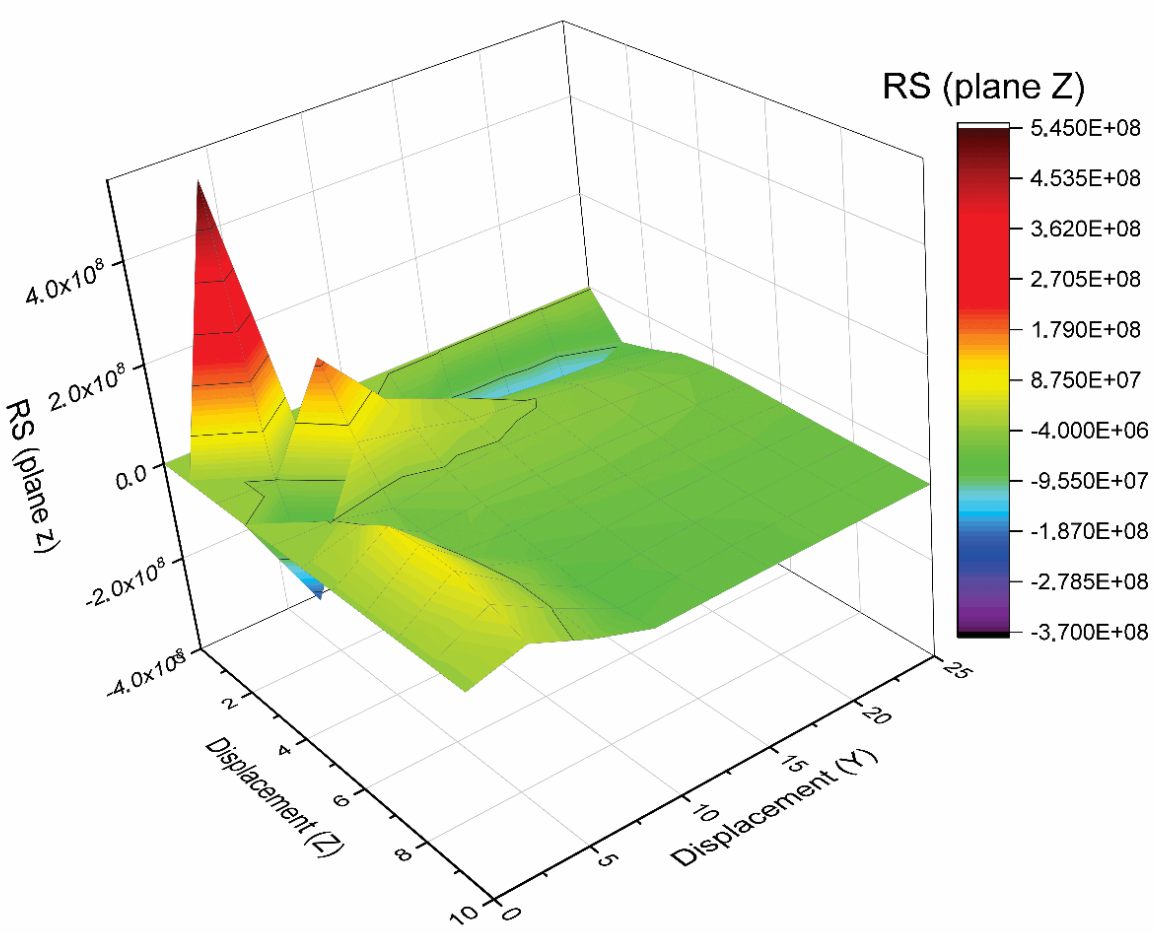

Figure 17 -3D representation of RS $(\mathrm{Pa})$ in the $\mathrm{Z}$ plane. The time of simulation $\mathrm{t}_{2}$ is $86400 \mathrm{~s}$. The colored bar on right is provided for comparison purposes.

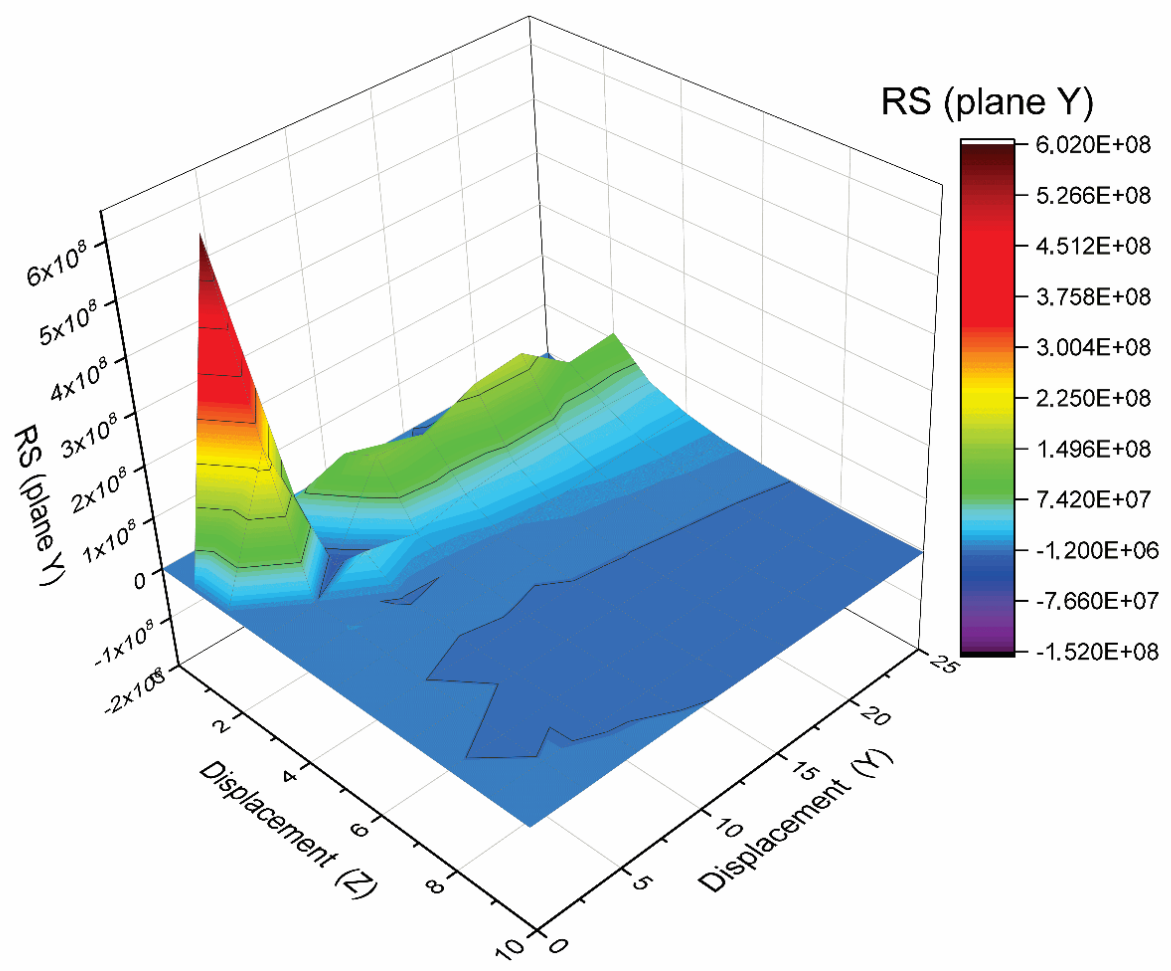

Figure 18 - 3D representation of the RS $(\mathrm{Pa})$ in the $\mathrm{Y}$ plane. The time of simulation $\mathrm{t}_{2}$ is $86400 \mathrm{~s}$. On right, the colored bar on the right is provided for comparison purposes. 


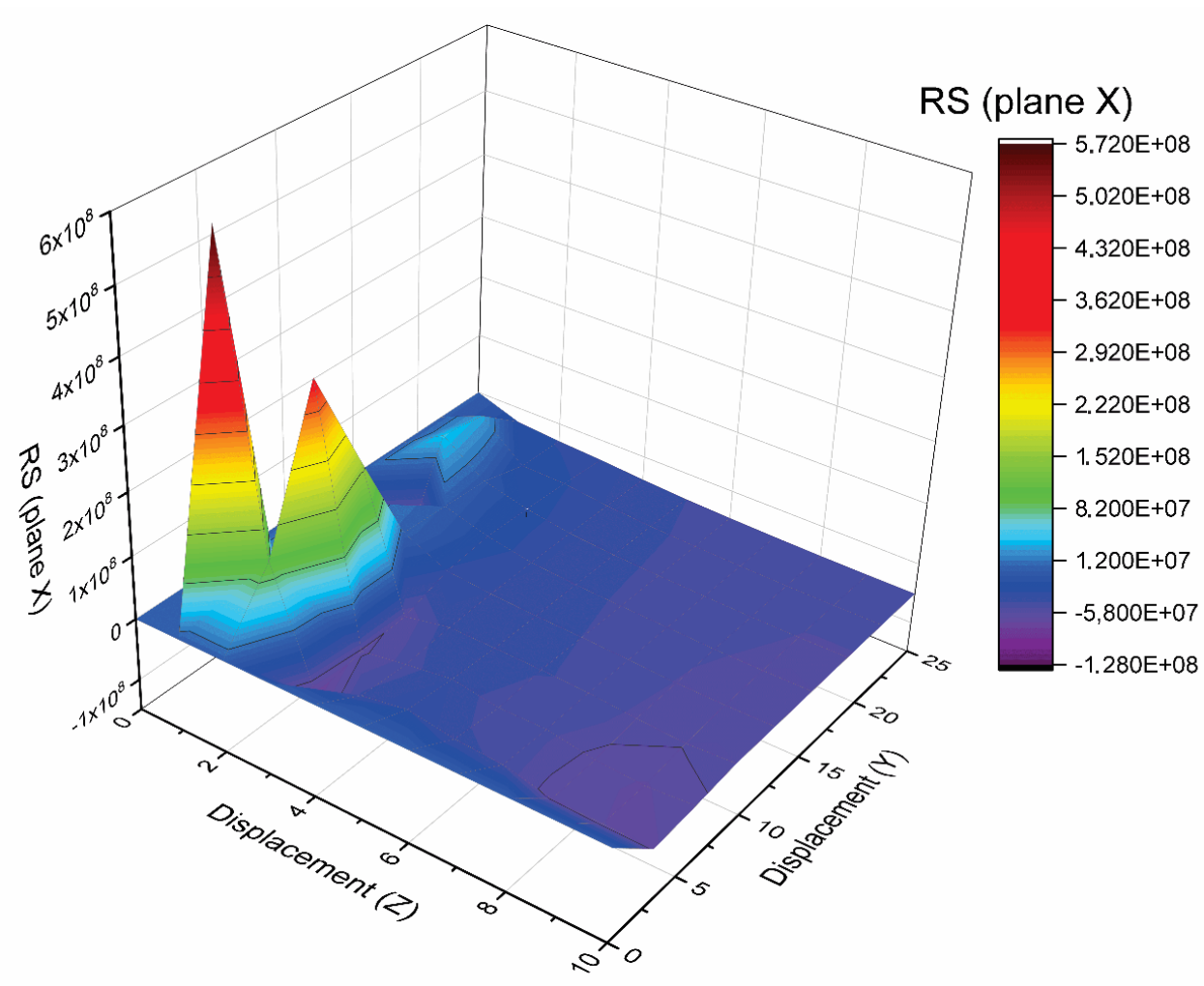

Figure 19 - 3D representation of the RS $(\mathrm{Pa})$ in the $\mathrm{X}$ plane, on right colored bar for comparison purposes, time $\mathrm{t}_{2}$ is $86400 \mathrm{~s}$.

The values of $\sigma_{1}, \sigma_{2}$ and $\sigma_{3}$ calculated in the spreadsheets from $\tau_{T R}$ and $\sigma_{T R}$ are shown in Figure 20, for the purpose of illustrating the changes that occurred point by point.

A significant reduction in the intensity of the values of $\sigma_{1}, \sigma_{2}$ and $\sigma_{3}$ appeared because of the distance from the locus of the fusion pool, showing that the influence of the RS decreases with distance. A rapid reduction of main stresses occurs from the fusion pool and as distance increase from it converges to the value of $100 \mathrm{MPa}$.

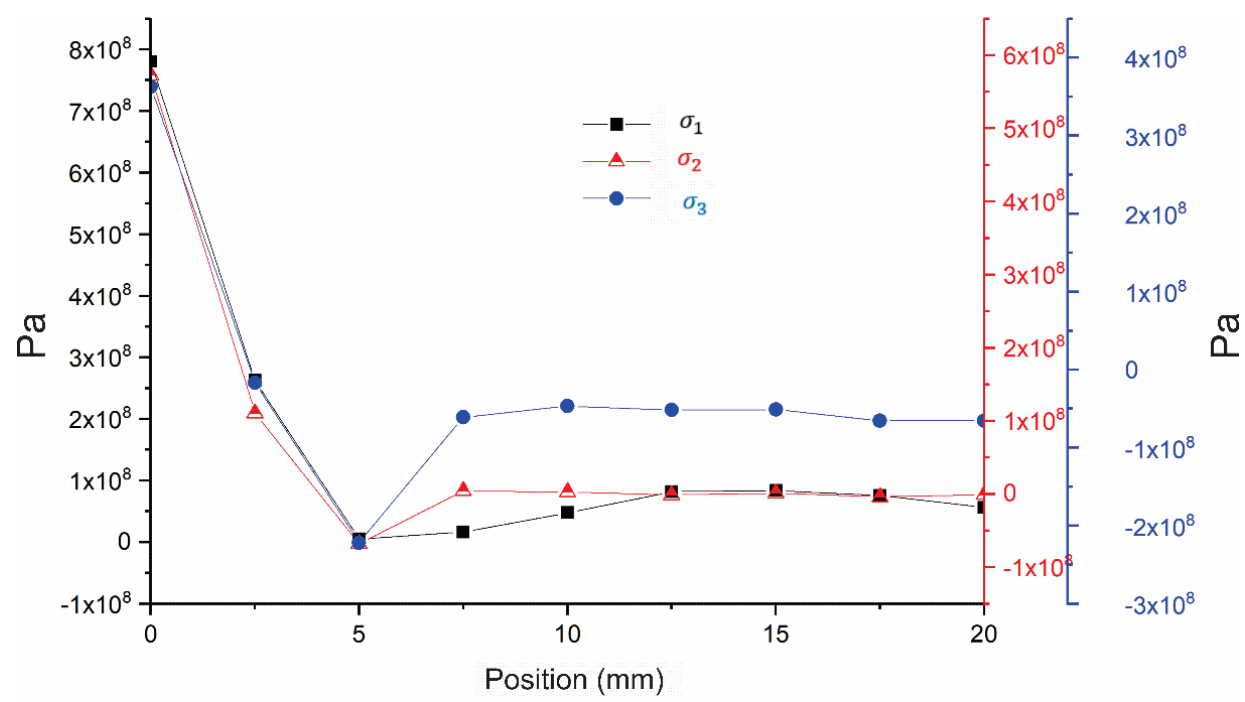

Figure 20 - Main stresses $\sigma_{1}, \sigma_{2}$ and $\sigma_{3}$ as a function of the distance from fusion pool.

The solutions developed in previous studies considered only the effects of constants $k_{f}, b$, and $\tau_{f} *$ in Table $\mathbf{1}$. We emphasize that the results shown here can undergo profound changes due to the above constants, as indicated in literature, but also depending on the position of the collection of RS and multiaxial stress values.

In addition to the above, we performed a set of 10000 simulations $\left(t_{1}\right)$, from which we obtained approximately 3340 oscillations. The cycles (peaks and valleys), grouped by the Multiaxial Rainflow method, were all multiplied by a fixed value representing the consecutive application of a set of 10000 stress fluctuations. 
Figure 21 shows the angles $(\Phi, \theta)$ varying from 0 ㅇ to 90 . Note that there is little variation in the angles $\theta$, which oscillates around the value of 85 . Note that only the points of the HAZ and MB and the solid surface are represented by points 20, 30, 40, 50, 60, 70, 80, 90 in Figure 9.

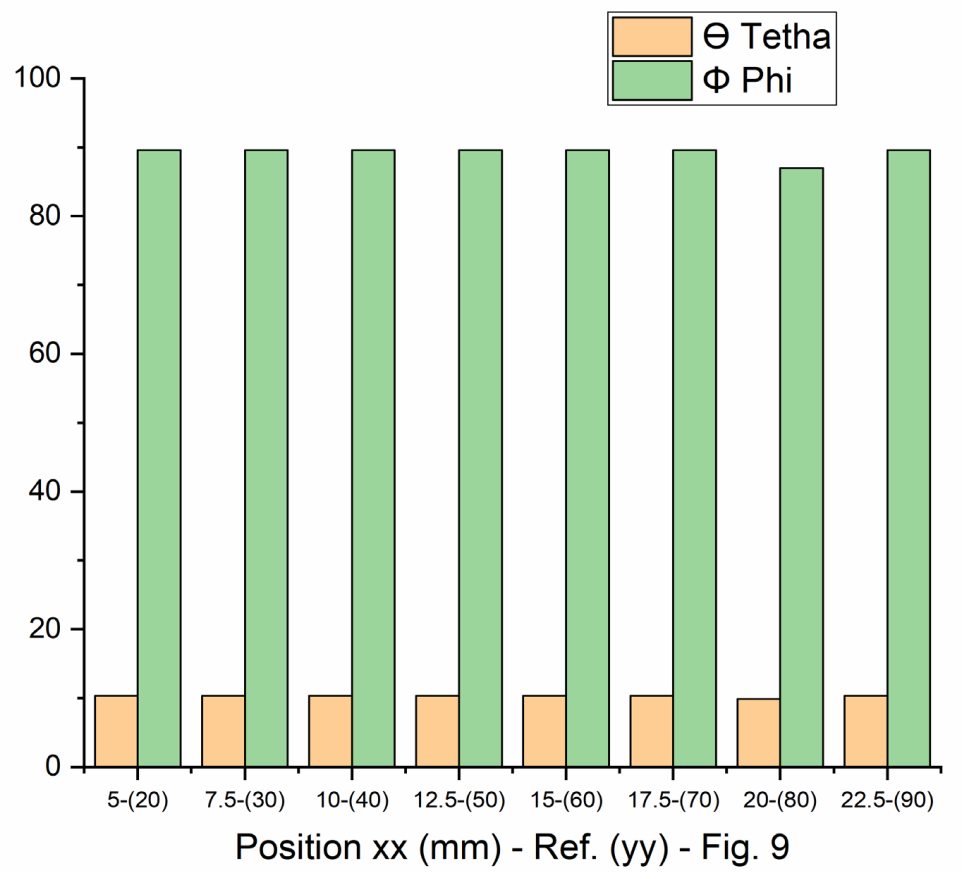

Figure 21 - Variation of crack propagation angles $(\Phi, \theta)$ as a function of position relative to the melt pool displacement line, without the influence of RS on the surface layer, as shown in Figure 9.

The variation of the crack propagation angles on the surface, shown in Figure 21, is only a variation as a function of position, so the reduced amplitude is in accordance with the theory, as there are no significant variations in the stress between various points.

In Figure 22, we illustrate in a schematic way the fatigue life predictions without the influence of the RS at the same points as in Figure 21. We note that there is a significant change in the fatigue life predictions in the points at a distance less than $17.5 \mathrm{~mm}$ from the line of locomotion of the fusion pool although there are no significant changes in the propagation angles of that crack.

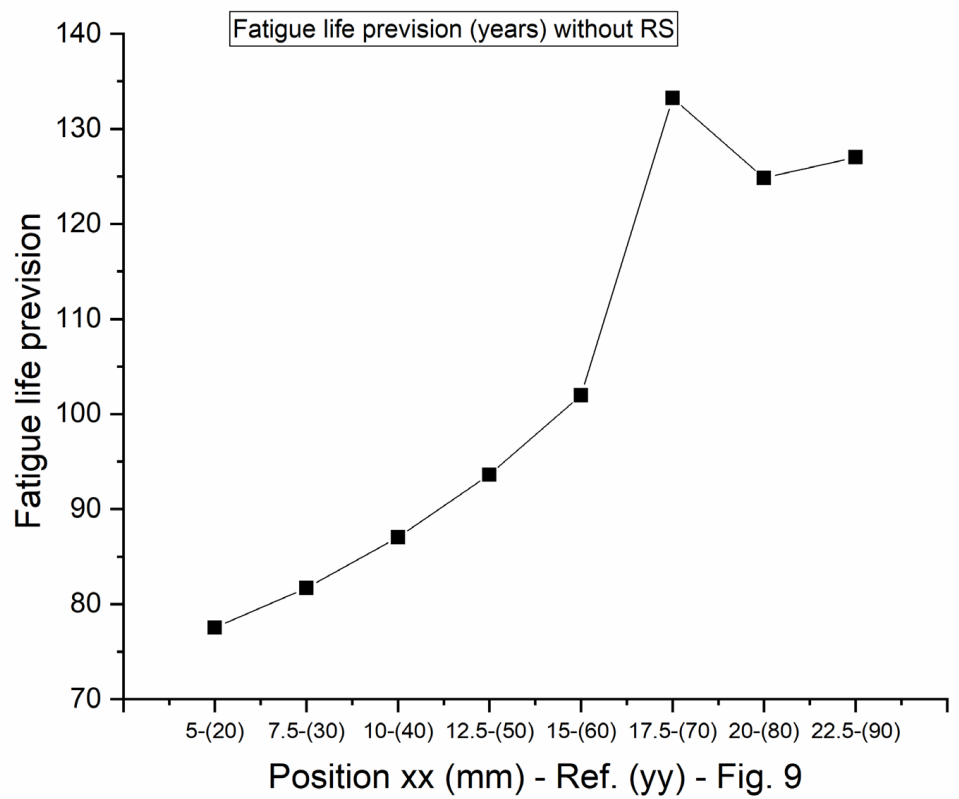

Figure 22 - Fatigue life prediction as a function of position in relation to the melt pool displacement line, without the influence of TR on the surface layer, as shown in Figure 9. 
Figure 23 shows the angles $(\Phi, \theta)$ varying from 0 을 to 90 . Note that there is a significant variation in the angles $(\Phi, \theta)$ oscillating around the value of $45^{\circ}$ on the surface of the solid at the points $20,30,40,50,60,70,80,90$ of Figure 9.

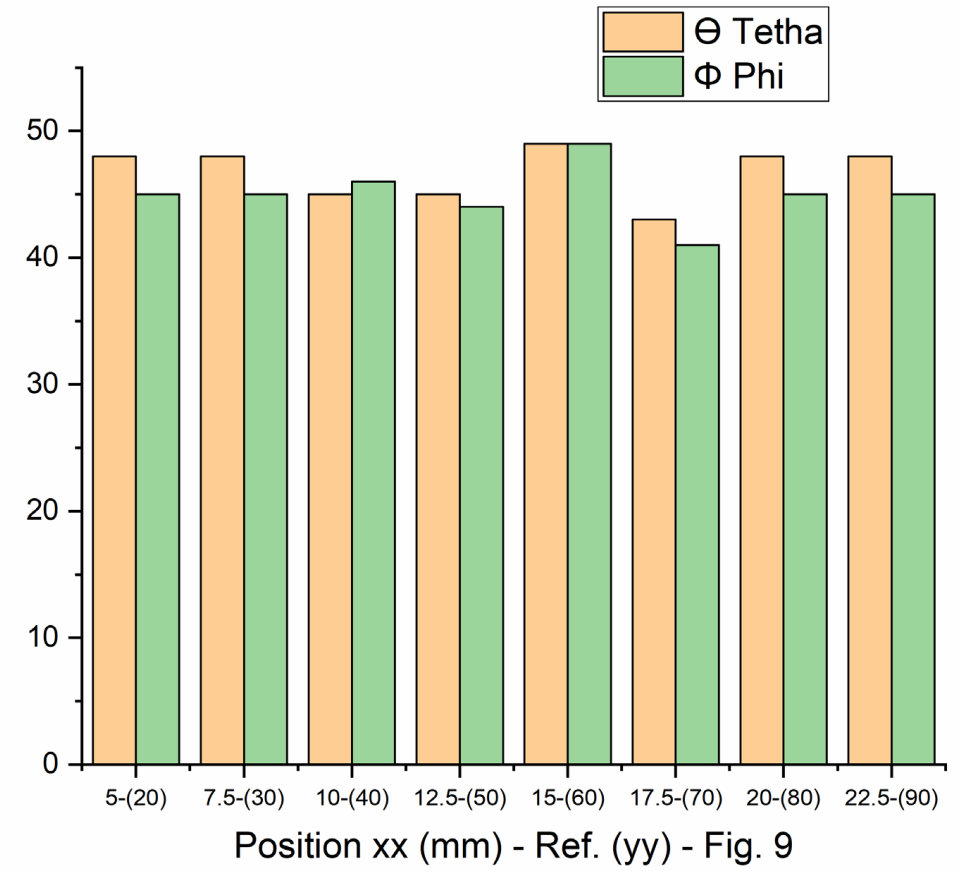

Figure 23- Variation of crack propagation angles $(\Phi, \Theta)$ as a function of position relative to the melt pool displacement line, with the influence of the TR of the superficial layer, as shown in Figure 9.

In Figure 24, representing the fatigue life prevision, we note that there is a significant variation starting from the maximum value of 55 years for $(\Phi, \theta)$ around the value of $45^{\circ}$ on the surface of the solid represented by the points 20 , 30, 40, 50, 60, 70, 80, 90 in Figure 9.

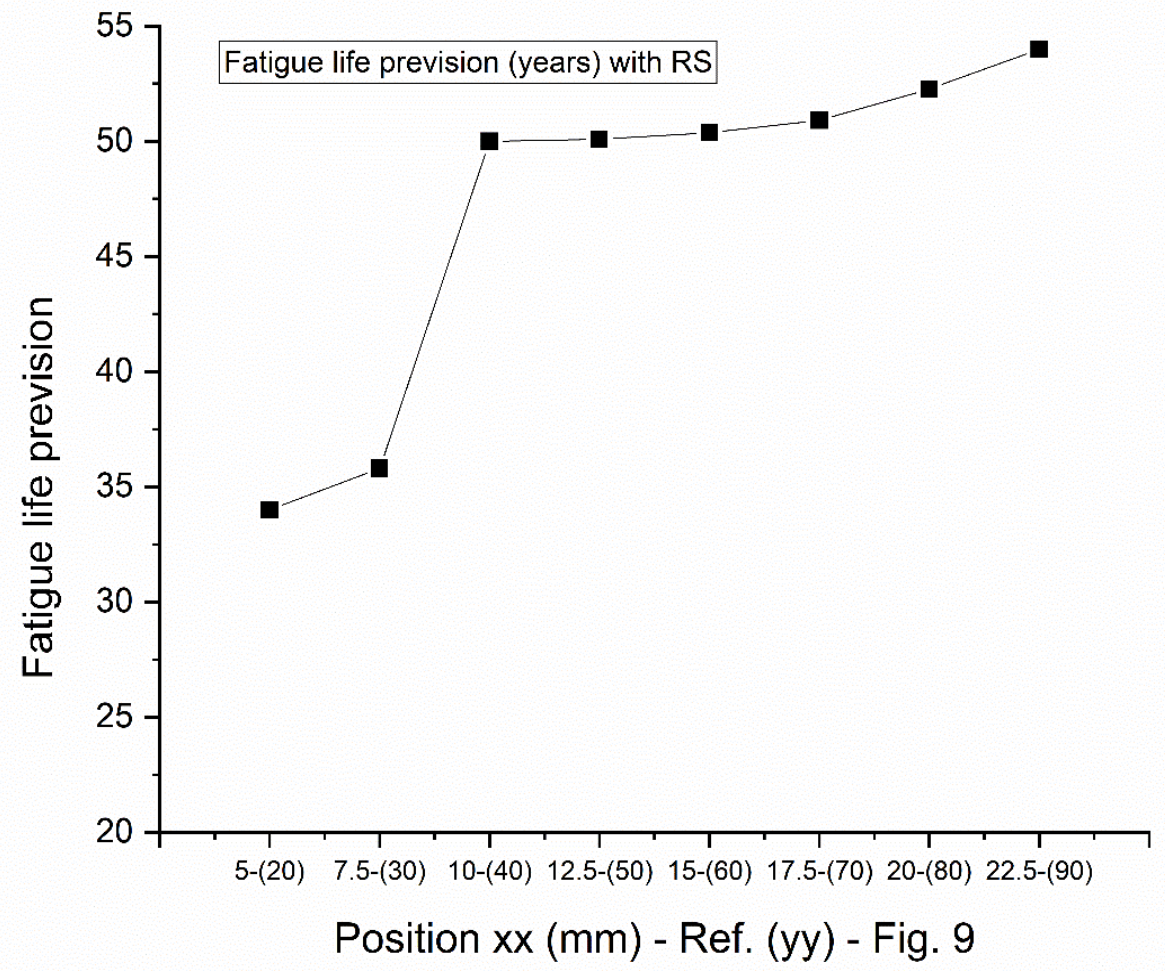

Figure 24- Fatigue life prevision in years, as a function of the position in relation to the displacement line of the fusion pool, without the influence of TR in the superficial layer, as shown in Figure 9. 
In a comparative analysis of Figure $\mathbf{2 4}$ and Figure 23, it can be seen that the existence of RS significantly changes the prediction of life in fatigue, with possible reduction by up to $50 \%$ of the expectation. In addition, there is a change in the trend observed in Figure 22, in which the values were of the order of magnitude of a hundred years for the reference points greater than 70. Such trend or the order of magnitude is not observed in Figure 24.

In the point-to-point comparative analysis of Figure $\mathbf{2 2}$ and Figure 24, it can be seen that the intensity of the RS at the point at $5 \mathrm{~mm}$ (reference point 20) reduced the fatigue life expectancy prevision.

In Figure 25, the evolution of fatigue life predictions in the points as a function of the angles $(\Phi, \theta)$ is shown in a two-dimensional form, clearly demonstrating the maximization of damage for the pairs of angles (10으, 85ㅇ) in the situation without TR.

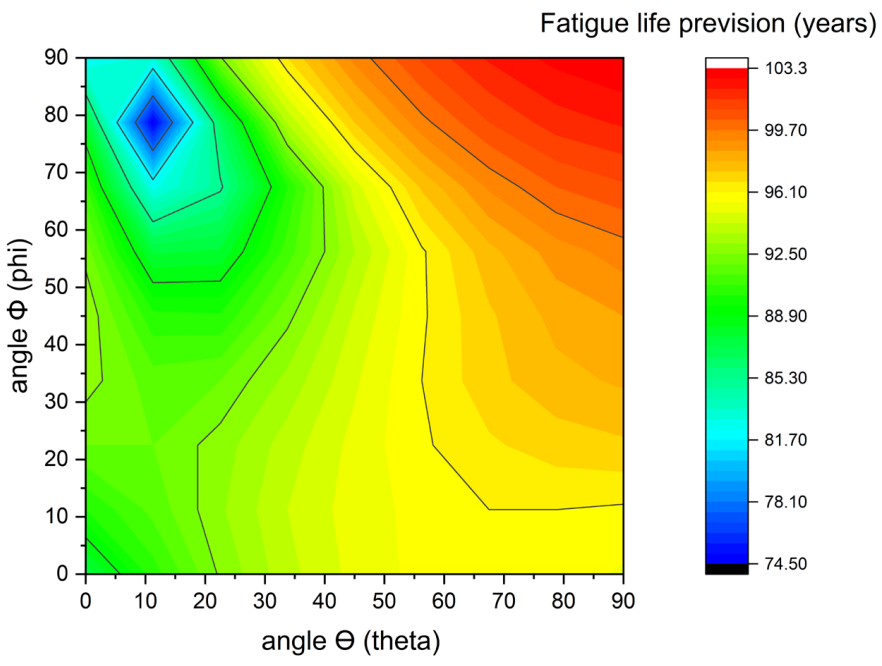

Figure 25- Change in the prediction of fatigue life as a function of the pair of angles $(\Phi, \theta)$ without RS.

\section{CONCLUSIONS}

This work brought a new level of understanding of relationship between the welding process and its effects on the fatigue phenomenon. Although there is specialized software for computer simulation via FEM of the welding process with the possibility of calculating the residual stresses (RS), it is rare for software to connect the RS with the countless multiaxial fatigue prediction models, as was achieved in this set of comprehensive connected simulations.

Existing computer simulation methods for welding, RS and fatigue are available in open code, versatile and suitable for immediate application in different geometries, steel families, process variables, with low cost, plausible adjustments, and possible additions or deletions of variables, which are fully coupled with the formation of RS.

There are countless works of fatigue life prediction in the base metal, but there are few and limited works that focus on understanding the consequences of the formation of the HAZ and the relationship with cyclical mechanical loads, especially in the phenomenon of high cycle fatigue. Thus, this work adds another piece of knowledge in understanding the relationship between welding/fatigue, as seen in the bibliographic analysis.

The methodology of this research was designed from the beginning foreseeing the possibility of fatigue life prediction, crack emergence position, and crack emergence angles. Special focus was on the HAZ region in the presence or absence of RS, a challenge which we have solved at the computational level.

We developed a method, in partially open code, to prevision the crack location and propagation in steel structure, welded or not. In addition, we were able to predict the angles of propagation of a high cycle fatigue crack with totally random loads, something that only a few models are able to deal with statistically, making this work applicable in the majority of everyday situations.

Finally, the current technical standards are solely and exclusively focused on the definition of methodologies for the phenomenon of uniaxial fatigue. Our intention is to propose the addition of a constant adjustment to the Findley models, only applicable to welded materials. This objective clearly represents an advancement in the state of the art picture.

This article reported a new approach to a more accurate estimate of the fatigue limit under non-proportional and out of phase multiaxial loads. 
The Fiedley criterion was carefully explored with preference for the Wang \& Brown and Multiaxial RainFlow methods. We observed that in the analysis without influences of RS, it produced good prevision of life in fatigue, but also allowed the addition of the specific influences of the RS.

\section{ACKNOWLEDGMENTS}

The authors acknowledge the financial support given by CAPES, FUPF and IFRS.

Author's contributions: Conceptualization and methodology, RC Tremarin, ZMC Pravia; Writing - original draft, RC Tremari; Writing- review and editing, RC Tremarin, ZMC Pravia.

Editor: Marcílio Alves.

\section{References}

AHLSTRÖM, Johan. Residual stresses generated by repeated local heating events - Modelling of possible mechanisms for crack initiation. Wear, [s. I.], v. 366-367, p. 180-187, 2016. DOI: 10.1016/J.WEAR.2016.05.029. Acesso em: 19 nov. 2019.

ANSYS. 2019. Acesso em: 27 mar. 2019.

ASTM E 1049-85. E1049-85: Standard Practices for Cycle Counting in Fatigue Analysis. E1049 - 85, [s. I.], v. 85, n. Reapproved 2011, p. 1-10, 1985. DOI: 10.1520/E1049-85R11E01.2

AUSIELLO, Pietro et al. Numerical fatigue 3D-FE modeling of indirect composite-restored posterior teeth. Dental Materials, [s. I.], v. 27, n. 5, p. 423-430, 2011. DOI: 10.1016/j.dental.2010.12.001

BAPTISTA, R. et al. Numerical study of fatigue crack initiation and propagation on optimally designed cruciform specimens. Procedia Structural Integrity, [s. I.], v. 1, p. 98-105, 2016. DOI: 10.1016/J.PROSTR.2016.02.014. Acesso em: 29 mar. 2018.

BHATTI, Ayjwat A. et al. Influence of thermo-mechanical material properties of different steel grades on welding residual stresses and angular distortion. 2015. [s. I.], 2015.DOI: 10.1016/j.matdes.2014.10.019

BOSCO JÚNIOR, Raul. Análise numérico-experimental de componentes sujeitos à fadiga por solicitações aleatórias: avaliação de modelos. [s. I.], 2007. Acesso em: 6 nov. 2019.

BROWN, M. W.; MILLER, K. J. A Theory for Fatigue Failure under Multiaxial Stress-Strain Conditions. Proceedings of the Institution of Mechanical Engineers, [s. I.], v. 187, n. 1, p. 745-755, 1973. DOI: 10.1243/PIME_PROC_1973_187_161_02. Acesso em: 25 out. 2018.

BS, 5400. British Standards Institution. BS 5400 (1980): Steel, concrete and composite bridges - Part 5: Code of practice for design of composite bridges. London, 2005.

BUI, Huy Duong. et al. Inverse problems in engineering mechanics : proceedings of the Second International Symposium on Inverse Problems--ISIP'94, Paris, France, 2-4 November 1994. [s.I.]: A.A. Balkema, 1994. Acesso em: 25 jul. 2018.

CAPRACE, Jean-David et al. A benchmark study of uncertainness in welding simulation. Marine Structures, [s. I.], v. 56, p. 6984, 2017. DOI: 10.1016/J.MARSTRUC.2017.07.005. Acesso em: 14 nov. 2018.

CHO, S. H.; KIM, J. W. Analysis of residual stress in carbon steel weldment incorporating phase transformations. Science and Technology of Welding and Joining, [s. I.], v. 7, n. 4, p. 212-216, 2002. DOI: 10.1179/136217102225004257

COMSOL. 2019. Acesso em: 27 mar. 2019.

CROSSLAND, Bernard. Effect of large hydrostatic pressures on the torsional fatigue strength of an alloy steel. In: PROC. INT. CONF. ON FATIGUE OF METALS 1956, Anais... [s.I: s.n.]

DARMADI, D. B.; KIET-TIEU, A.; NORRISH, J. A validated thermo mechanical FEM model of bead-on-plate welding. International Journal of Materials \& Product Technology, [s. I.], v. 48, n. 1-4, p. 146-166, 2014. DOI: Doi 10.1504/ljmpt.2014.059047 
DENG, Dean et al. Investigating the influence of external restraint on welding distortion in thin-plate bead-on joint by means of numerical simulation and experiment. The International Journal of Advanced Manufacturing Technology, [s. I.], v. 82, n. 58, p. 1049-1062, 2016. DOI: 10.1007/s00170-015-7413-7. Acesso em: 7 nov. 2018.

DENG, Dean. FEM prediction of welding residual stress and distortion in carbon steel considering phase transformation effects. Materials \& Design, [s. I.], v. 30, n. 2, p. 359-366, 2009. DOI: 10.1016/J.MATDES.2008.04.052. Acesso em: 7 jan. 2019.

DENG, Dean; MURAKAWA, Hidekazu. Numerical simulation of temperature field and residual stress in multi-pass welds in stainless steel pipe and comparison with experimental measurements. Computational Materials Science, [s. I.], v. 37, n. 3, p. 269-277, 2006. DOI: 10.1016/J.COMMATSCI.2005.07.007. Acesso em: 7 jan. 2019.

EISAZADEH, H. et al. Effect of material properties and mechanical tensioning load on residual stress formation in GTA $304-A 36$ dissimilar weld. Journal of Materials Processing Technology, [s. I.], v. 222, p. 344-355, 2015. DOI:

10.1016/j.jmatprotec.2015.03.021

ESMAEILI, F. et al. Prediction of fatigue life for multi-spot welded joints with different arrangements using different multiaxial fatigue criteria. Materials and Design, [s. I.], v. 72, p. 21-30, 2015. DOI: 10.1016/j.matdes.2015.02.008

EUROCODE 3. EN 1993-1-9 (2005): Eurocode 3: Design of steel structures - Part 1-9 : FatigueBrussels, 2005.

FATEMI, Ali; SOCIE, Darrell F. a Critical Plane Approach To Multiaxial Fatigue Damage Including Ou of Phase Loading. Fatigue \& Fracture of Engineering Materials \& Structures, [s. I.], v. 11, n. 3, p. 149-165, 1988. DOI: 10.1111/j.1460-2695.1988.tb01169.x

FINDLEY, W. N. A Theory for the Effect of Mean Stress on Fatigue of Metals Under Combined Torsion and Axial Load or Bending. Journal of Engineering For Industry, [s. I.], p. 301-306, 1959.

GADALLAH, Ramy et al. A novel approach to evaluate mixed-mode SIFs for a through-thickness crack in a welding residual stress field using an effective welding simulation method. Engineering Fracture Mechanics, [s. I.], v. 197, p. 48-65, 2018. DOI: 10.1016/J.ENGFRACMECH.2018.04.040. Acesso em: 30 out. 2018.

GAN, Jin et al. The effect of shot peening on fatigue life of Q345D T-welded joint. Journal of Constructional Steel Research, [s. I.], v. 126, p. 74-82, 2016. DOI: 10.1016/J.JCSR.2016.07.010. Acesso em: 7 ago. 2018.

GANNON, Liam et al. Effect of welding sequence on residual stress and distortion in flat-bar stiffened plates. Marine Structures, [s. I.], v. 23, n. 3, p. 385-404, 2010. DOI: 10.1016/J.MARSTRUC.2010.05.002. Acesso em: 8 jan. 2019.

GOEDEL, Fábio et al. Fatigue lifespan of a fillet welded joint - Hybrid approach to obtain the S-N curve with a reduced number of tests. Latin American Journal of Solids and Structures, [s. I.], v. 15, n. 10, 2018. DOI: 10.1590/1679-78255194. Acesso em: 5 abr. 2019.

GOLDAK, John; CHAKRAVARTI, Aditya; BIBBY, Malcolm. A new finite element model for welding heat sources. Metallurgical Transactions B, [s. I.], v. 15, n. 2, p. 299-305, 1984. DOI: 10.1007/BF02667333

$\mathrm{HE}$, Chao et al. Fatigue damage evaluation of low-alloy steel welded joints in fusion zone and heat affected zone based on frequency response changes in gigacycle fatigue. International Journal of Fatigue, [s. I.], v. 61, p. 297-303, 2014. DOI: 10.1016/j.ijfatigue.2013.10.018

HILDEBRAND, Jörg; SOLTANZADEH, Hadi. A review on assessment of fatigue strength in welded studsInternational Journal of Steel Structures, 2014. DOI: 10.1007/s13296-014-2020-2

HOBBACHER, Adolf F. et al. Transfer of Australasian bridge design to fatigue verification system of Eurocode 3. Journal of Constructional Steel Research, [s. I.], v. 122, p. 532-542, 2016. DOI: 10.1016/j.jcsr.2016.03.023

HUA, Jiang et al. Effect of feed rate, workpiece hardness and cutting edge on subsurface residual stress in the hard turning of bearing steel using chamfer + hone cutting edge geometry. Materials Science and Engineering: A, [s. I.], v. 394, n. 1-2, p. 238248, 2005. DOI: 10.1016/J.MSEA.2004.11.011. Acesso em: 26 jan. 2019.

HUANG, Xianfu; LIU, Zhanwei; XIE, Huimin. Recent progress in residual stress measurement techniques. Acta Mechanica Solida Sinica, [s. I.], v. 26, n. 6, p. 570-583, 2013. DOI: 10.1016/S0894-9166(14)60002-1. Acesso em: 29 jan. 2019.

HUO, Lixing; WANG, Dongpo; ZHANG, Yufeng. Investigation of the fatigue behaviour of the welded joints treated by TIG dressing and ultrasonic peening under variable-amplitude load. International Journal of Fatigue, [s. I.], v. 27, n. 1, p. 95-101, 2005. DOI: 10.1016/j.ijfatigue.2004.05.009

JAMES, M. N. et al. Residual stresses and fatigue performance. Engineering Failure Analysis, [s. I.], v. 14, n. 2, p. 384-395, 2007. DOI: 10.1016/J.ENGFAILANAL.2006.02.011. Acesso em: 4 fev. 2019. 
JAVADI, Yashar; HASANI, Mahmood; SADEGHI, Seyedali. Investigation of Clamping Effect on the Welding Sub-surface Residual Stress and Deformation by Using the Ultrasonic Stress Measurement and Finite Element Method. Journal of Nondestructive Evaluation, [s. I.], v. 34, n. 1, p. 3, 2015. DOI: 10.1007/s10921-015-0277-9. Acesso em: 7 nov. 2018.

JIA, Xiaolei et al. A new method to estimate heat source parameters in gas metal arc welding simulation process. Fusion Engineering and Design, [s. I.], v. 89, n. 1, p. 40-48, 2014. DOI: 10.1016/J.FUSENGDES.2013.11.006. Acesso em: 9 nov. 2018.

JOSHI, Suraj et al. Characterization of material properties and heat source parameters in welding simulation of two overlapping beads on a substrate plate. Computational Materials Science, [s. I.], v. 69, p. 559-565, 1970. DOI: 10.1016/j.commatsci.2012.11.029

KHURSHID, M. et al. The multiaxial weld root fatigue of butt welded joints subjected to uniaxial loading. Fatigue and Fracture of Engineering Materials and Structures, [s. I.], v. 39, n. 10, p. 1281-1298, 2016. DOI: 10.1111/ffe.12444. Acesso em: 7 ago. 2018.

KLUGER, Krzysztof; ŁAGODA, Tadeusz. Fatigue life estimation for selected materials in multiaxial stress states with mean stress. Journal of Theoretical and Applied Mechanics, [s. I.], p. 385, 2016. DOI: 10.15632/jtam-pl.54.2.385

KNOEDEL, Peter; GKATZOGIANNIS, Stefanos; UMMENHOFER, Thomas. Practical aspects of welding residual stress simulation. Journal of Constructional Steel Research, [s. I.], v. 132, p. 83-96, 2017. DOI: 10.1016/J.JCSR.2017.01.010. Acesso em: 30 out. 2018.

KOHANDEHGHAN, A. R.; SERAJZADEH, S. Arc welding induced residual stress in butt-joints of thin plates under constraints. Journal of Manufacturing Processes, [s. I.], v. 13, n. 2, p. 96-103, 2011. DOI: 10.1016/j.jmapro.2011.01.002. Acesso em: 13 nov. 2018.

KREBS, J.; KASSNER, M. Influence of Welding Residual Stresses on Fatigue Design of Welded Joints and Components. Welding in the World, [s. I.], v. 51, n. 7-8, p. 54-68, 2007. DOI: 10.1007/BF03266586

KRZYZANOWSKI, M.; BEYNON, J. H. Finite element model of steel oxide failure during tensile testing under hot rolling conditions. Materials Science and Technology, [s. I.], v. 15, n. 10, 1999. DOI: 10.1179/026708399101505103

$\mathrm{LI}$, Suo et al. Numerical investigation of formation mechanism of welding residual stress in P92 steel multi-pass joints. Journal of Materials Processing Technology, [s. I.], v. 244, p. 240-252, 2017. DOI: 10.1016/J.JMATPROTEC.2017.01.033. Acesso em: 14 nov. 2018.

LINDGREN, L. E. E. Numerical modelling of welding. Computer Methods in Applied Mechanics and Engineering, [s. I.], v. 195, n. 48-49, p. 6710-6736, 2006. DOI: 10.1016/j.cma.2005.08.018. Acesso em: 13 nov. 2018.

LIU, Sumei et al. Numerical simulation and experimental research on temperature and stress fields in TIG welding for plate of RAFM steel. Fusion Engineering and Design, [s. I.], v. 136, p. 690-693, 2018. DOI: 10.1016/J.FUSENGDES.2018.03.058. Acesso em: 31 out. 2018.

LOPEZ-JAUREGI, A. et al. Fatigue analysis of multipass welded joints considering residual stresses. International Journal of Fatigue, [s. I.], v. 79, p. 75-85, 2015. DOI: 10.1016/j.ijfatigue.2015.04.013

MAMIYA, E. N.; ARAÚJO, J. A.; CASTRO, F. C. Prismatic hull: A new measure of shear stress amplitude in multiaxial high cycle fatigue. International Journal of Fatigue, [s. I.], v. 31, n. 7, p. 1144-1153, 2009. DOI: 10.1016/j.ijfatigue.2008.12.010

MCDIARMID, D. L. A General Critrerion For High Cycle Multiaxial Fatigue Failure. Fatigue \& Fracture of Engineering Materials and Structures, [s. I.], v. 14, n. 4, p. 429-453, 1991. DOI: 10.1111/j.1460-2695.1991.tb00673.x. Acesso em: 26 jul. 2018.

MIKAMI, Yoshiki; NAKAMURA, Terumi; MOCHIZUKI, Masahito. Numerical investigation of the influence of heat source modeling on simulated residual stress distribution in weaving welds. Welding in the World, [s. I.], v. 60, n. 1, p. 41-49, 2016. DOI: 10.1007/s40194-015-0274-8. Acesso em: 9 nov. 2018.

MIKIHITO, Hirohata; YOSHITO, Itoh. A simplified FE simulation method with shell element for welding deformation and residual stress generated by multi-pass butt welding. International Journal of Steel Structures, [s. I.], v. 16, n. 1, p. 51-58, 2016. DOI: 10.1007/s13296-016-3005-0

$\mathrm{NI}$, J.; WAHAB, M. A. The prediction of residual stress and its influence on the mechanical properties of weld joint. Journal of Physics: Conference Series, [s. I.], v. 843, n. 1, p. 012001, 2017. DOI: 10.1088/1742-6596/843/1/012001. Acesso em: 9 nov. 2018. 
PAPADOPOULOS, loannis V. Long life fatigue under multiaxial loading. International Journal of Fatigue, [s. I.], v. 23, n. 10, p. 839-849, 2001. DOI: 10.1016/S0142-1123(01)00059-7. Acesso em: 27 jul. 2018.

PEDERSEN, M. M. Multiaxial fatigue assessment of welded joints using the notch stress approach. International Journal of Fatigue, [s. I.], v. 83, p. 269-279, 2016. DOI: 10.1016/j.ijfatigue.2015.10.021

QIAN, Xudong et al. Fatigue and residual strength of concrete-filled tubular X-joints with full capacity welds. Journal of Constructional Steel Research, [s. I.], v. 100, p. 21-35, 2014. DOI: 10.1016/j.jcsr.2014.04.021

ROSENTHAL, D. The Theory of Moving Sources of Heat and Its Application to Metal Treatments. Transactions of the American Society of Mechanical Engineers, [s. I.], v. 68, p. 849-866, 1946. DOI: 10.4236/eng.2011.32017

ROSSINI, N. S. et al. Methods of measuring residual stresses in components. Materials \& Design, [s. I.], v. 35, p. 572-588, 2012. DOI: 10.1016/j.matdes.2011.08.022. Acesso em: 6 dez. 2018.

SADIQ, H. et al. Determination of Steel Emissivity for the Temperature Prediction of Structural Steel Members in Fire. Journal of Materials in Civil Engineering, [s. I.], v. 25, n. 2, p. 167-173, 2013. DOI: 10.1061/(ASCE)MT.1943-5533.0000607. Acesso em: 9 abr. 2019.

SAVARIA, Vincent; BRIDIER, Florent; BOCHER, Philippe. Predicting the effects of material properties gradient and residual stresses on the bending fatigue strength of induction hardened aeronautical gears. International Journal of Fatigue, [s. I.], v. 85, p. 70-84, 2016. DOI: 10.1016/J.IJFATIGUE.2015.12.004. Acesso em: 23 nov. 2018.

SEIF, Mina; MCALLISTER, Therese. Stability of wide flange structural steel columns at elevated temperatures. Journal of Constructional Steel Research, [s. I.], v. 84, p. 17-26, 2013. DOI: 10.1016/J.JCSR.2013.02.002. Acesso em: 20 mar. 2019.

SERINDAG, Huseyin Tarik et al. Friction Stir Welding of AZ31 Magnesium Alloys - A Numerical and Experimental Study. Latin American Journal of Solids and Structures, [s. I.], v. 14, n. 1, p. 113-130, 2017. DOI: 10.1590/1679-78253162. Acesso em: 16 dez. 2019.

SHEN, Wei et al. Fatigue life evaluation of welded joints considering the local multiaxial stress/strain states and numerically determined residual stresses/strains. International Journal of Steel Structures, [s. I.], v. 17, n. 1, p. 139-153, 2017. DOI: 10.1007/s13296-015-0162-5. Acesso em: 29 mar. 2018.

SILVA, Luiz Leite Da et al. Development and Test of an Equipment to Measure Residual Strain Inside Pipes Using the HoleDrilling Method. Latin American Journal of Solids and Structures, [s. I.], v. 13, n. 13, p. 2439-2450, 2016. DOI: 10.1590/167978253126. Acesso em: 7 ago. 2018.

SINES, G. Behavior of metals under complex static and alternating stresses. Metal fatigue, [s. I.], v. 1, p. 145-169, 1959.

SOCIE, D. F. \& MARQUIS, G. B. Multiaxial Fatigue. [s.I.]: Warrendale - SAE International, 2000.

SONSINO, C. M. Effect of residual stresses on the fatigue behaviour of welded joints depending on loading conditions and weld geometry. International Journal of Fatigue, [s. I.], v. 31, n. 1, p. 88-101, 2009. DOI: 10.1016/j.ijfatigue.2008.02.015

SRIVASTAVA, Jay Prakash et al. Rolling Contact Fatigue Life of Rail for Different Slip Conditions. Latin American Journal of Solids and Structures, [s. I.], v. 14, n. 12, p. 2243-2264, 2017. DOI: 10.1590/1679-78254161. Acesso em: 16 dez. 2019.

SYSWELD. 2019. Acesso em: 27 mar. 2019.

TCHOUPOU, Kévin Martial Tsapi et al. Fatigue Equivalent Stress State Approach Validation in Non-conservative Criteria: a Comparative Study. Latin American Journal of Solids and Structures, [s. I.], v. 12, n. 13, p. 2506-2519, 2015. DOI: 10.1590/1679-78251784. Acesso em: 19 nov. 2019.

TREMARIN, Ronaldo Cesar; PRAVIA, Zacarias Martin Chamberlain. Previsões de Vida Fadiga Segundo Normas Técnicas: uma Revisão Crítica. Soldagem \& Inspeção, [s. I.], v. 22, n. 3, p. 281-299, 2017. DOI: 10.1590/0104-9224/si2203.06. Acesso em: 12 abr. 2018.

WANG, C. H.; BROWN, M. W. Multiaxial random load fatigue: life prediction techniques and experimentsMultiaxial Fatigue and Design, 1996.

winLIFE - stz-verkehr. 2019. Acesso em: 12 dez. 2018.

WITHERS, P. J.; BHADESHIA, H. K. D. H. Residual stress. Part 1 - Measurement techniques. Materials Science and Technology, [s. I.], v. 17, n. 4, p. 355-365, 2001. DOI: 10.1179/026708301101509980. Acesso em: 1 mar. 2019. 
WITHERS, Philip J. Mapping residual and internal stress in materials by neutron diffraction. Comptes Rendus Physique, [s. I.], v. 8, n. 7-8, p. 806-820, 2007. DOI: 10.1016/J.CRHY.2007.09.015. Acesso em: 4 fev. 2019.

YADAIAH, N.; BAG, S. Development of egg-configuration heat source model in numerical simulation of autogenous fusion welding process. International Journal of Thermal Sciences, [s. I.], v. 86, p. 125-138, 2014. DOI:

10.1016/J.IJTHERMALSCI.2014.06.032. Acesso em: 31 out. 2018. 